\title{
Re-emergence of North Atlantic subsurface ocean temperature anomalies in a seasonal forecast system
}

\author{
Jeremy P. Grist ${ }^{1}$ (D) Bablu Sinha ${ }^{1} \cdot$ Helene. T. Hewitt ${ }^{2} \cdot$ Aurélie Duchez $^{1} \cdot$ Craig MacLachlan $^{2} \cdot$ Patrick Hyder $^{2}$. \\ Simon A. Josey ${ }^{1}$ · Joël J.-M. Hirschi ${ }^{1} \cdot$ Adam T. Blaker $^{1} \cdot$ Adrian. L. New $^{1}$ · Adam A. Scaife ${ }^{2,3}$ • Chris D. Roberts ${ }^{2,4}$
}

Received: 28 August 2018 / Accepted: 20 May 2019 / Published online: 4 June 2019

(c) The Author(s) 2019

\begin{abstract}
A high-resolution coupled ocean atmosphere model is used to study the effects of seasonal re-emergence of North Atlantic subsurface ocean temperature anomalies on northern hemisphere winter climate. A 50-member control ensemble is integrated from 1 September 2007 to 28 February 2008 and compared with a parallel ensemble with perturbed ocean initial conditions. The perturbation consists of a density-compensated subsurface Atlantic temperature anomaly corresponding to the observed subsurface temperature anomaly for September 2010. The experiment is repeated for two atmosphere horizontal resolutions $(\sim 60 \mathrm{~km}$ and $\sim 25 \mathrm{~km})$ in order to determine whether the sensitivity of the atmosphere to re-emerging temperature anomalies is dependent on resolution. A wide range of re-emergence behavior is found within the perturbed ensembles. While the observations seem to indicate that most of the re-emergence is occurring in November, most members of the ensemble show re-emergence occurring later in the winter. However, when re-emergence does occur it is preceded by an atmospheric pressure pattern that induces a strong flow of cold, dry air over the mid-latitude Atlantic, and enhances oceanic latent heat loss. In response to re-emergence (negative SST anomalies), there is reduced latent heat loss, less atmospheric convection, a reduction in eddy kinetic energy and positive low-level pressure anomalies downstream. Within the framework of a seasonal forecast system the results highlight the atmospheric conditions required for re-emergence to take place and the physical processes that may lead to a significant effect on the winter atmospheric circulation.
\end{abstract}

Keywords Seasonal forecasting $\cdot$ Climate model $\cdot$ Re-emergence

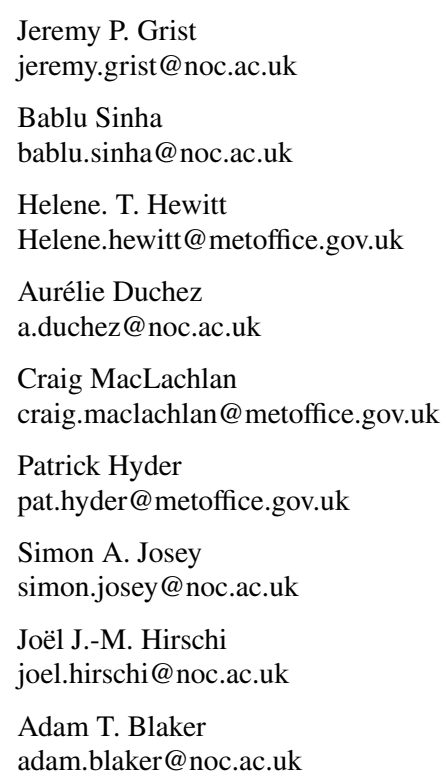

Adrian. L. New

adrian.new@noc.ac.uk

Adam A. Scaife

adam.scaife@metoffice.gov.uk

Chris D. Roberts

chris.roberts@ecmwf.int

1 National Oceanography Centre, European Way, Southampton SO14 3ZH, UK

2 Met Office, Hadley Centre, Fitzroy Road, Exeter EX1 3PB, UK

3 College of Engineering, Mathematics and Physical Sciences, University of Exeter, Exeter, UK

4 European Centre for Medium Range Weather Forecasts (ECMWF), Shinfield Park, Reading, UK 


\section{Introduction}

Recent developments in high-resolution coupled climate modeling have led to skillful seasonal forecasts for the North Atlantic region and in particular for the leading mode of North Atlantic climate variability, the North Atlantic Oscillation (NAO, Scaife et al. 2014). When initialized with observed November ocean conditions, the Met Office Global Seasonal forecast system version 5 (GloSea5) (MacLachlan et al. 2015) can predict the winter (December-January-February, DJF) NAO Index with a correlation skill of 0.6 (Scaife et al. 2014) and the winter AO with similar skill (MacLachlan et al. 2015).

This high skill, however, is only realized by employing large ensembles of numerical simulations, due to an apparently low signal to noise ratio in the forecast (Eade et al. 2014; Siegert et al. 2016) compared to the real world, in common with other state-of-the-art seasonal forecast systems (e.g. Kumar and Chen 2017). Although it is unresolved, it is possible that this low signal to noise ratio occurs because the forecast model is unable to accurately capture the air-sea interaction processes which mediate the transfer of heat between ocean and atmosphere (Minobe et al. 2008), and that higher resolution in the atmosphere and/or ocean components of the prediction system is required (Hewitt et al. 2017).

A number of physical processes appear to contribute to the skill in winter seasonal forecasts of the NAO. In particular processes such as El-Niño (Ineson and Scaife 2009); solar forcing (Gray et al. 2016); the Quasi-Biennial Oscillation (Marshall and Scaife 2009); sea-ice/snow cover (Bojariu and Gimeno 2003) and tropical Rossby wave sources (Scaife et al. 2017) have been identified.

One mechanism that has received extensive attention is forcing of the atmosphere by anomalous sea-surface temperature patterns (Czaja and Frankignoul 2002; Rodwell et al. 1999; Cassou et al. 2007). A clear example of an event where it is likely that this mechanism dominated is the cold European winter of 2010-2011. Maidens et al. (2013) demonstrated that the cause of the extreme negative NAO over that winter was at least partly driven by the evolution of the North Atlantic SST field. Buchan et al. (2014) suggested that the mechanism was the surface reemergence of low temperature anomalies that had been imprinted in the mixed layer in winter 2009-2010 by the strongly negative NAO conditions prevailing in that winter (Fereday et al. 2012). These low temperatures were capped during the intervening summer as the mixed layer shoaled, but persisted below the seasonal thermocline and were re-entrained into the mixed layer with the onset of winter mixing in late 2010 (Taws et al. 2011).
It is possible that knowledge of an anomalously cold summer subsurface, for example resulting from strong surface cooling in the previous winter, could be harnessed to predict both the nature of the following winter re-emergence and its impact on the region's climate. For example, given the details of observed subsurface temperature anomaly at the end of winter 2013-2014, Grist et al. (2016) assumed the anomaly would disperse passively, based probabilistically on the currents of a 30-year eddy resolving forced ocean model simulation. Defining re-emergence as the time and location that the advected anomaly was re-entrained in the mixed layer allowed a negative SST anomaly for the subpolar North Atlantic to be predicted for November 2014. A negative SST anomaly did appear in November 2014 near the predicted location.

In the current study, we seek to use information about a summer subsurface temperature anomaly in a fully coupled system, with a view to revealing the ability of re-emergence to impact the regional climate. Specifically, a densitycompensated subsurface temperature anomaly is inserted beneath the end-of-summer North Atlantic mixed layer in the initial conditions of a 6-month integration of the UK Met Office GloSea5 seasonal forecasting system. In order to assess the sensitivity of the air-sea interaction processes and signal-to-noise ratio to atmospheric resolution, a multimember ensemble experiment is conducted with both a standard N216 $(\sim 60 \mathrm{~km})$ resolution and a higher resolution $\mathrm{N} 512(\sim 25 \mathrm{~km})$ atmosphere using the same ocean state. This is particularly relevant as recent work suggests this higher resolution maybe important for more accurately simulating the role of air-sea interactions in the development of midlatitude atmospheric systems (Parfitt et al. 2016).

The structure of the paper is as follows. In Sect. 2 there is a description of the coupled model used in the experiment and in Sect. 3 the details of the experimental setup are explained. The experimental results are described in Sect. 4. The findings are summarized in Sect. 5.

\section{Model description}

We employ the UK Met Office GloSea5 seasonal forecasting system (MacLachlan et al. 2015), which at its core is the Global Coupled model version 2 (GC2, Williams et al. 2015). GC2 is a state-of-the-art climate prediction system based on the UK Met Office's Global Atmosphere model version 6.0 (GA6, Walters et al. 2017, Global Land 6.0), coupled to the shared ocean configuration, Global Ocean model version 5.0 (GO5, Megann et al. 2014), which at its core is NEMO (Nucleus for European Modelling of the Ocean, Madec 2008). The ocean is implemented on the tripolar ORCA25 horizontal grid (Madec and Imbard 1996), with a nominal $1 / 4^{\circ}$ horizontal resolution and 75 vertical 
levels ranging in thickness from $1 \mathrm{~m}$ at the surface to $200 \mathrm{~m}$ at depth. Ice is represented using Global Sea-Ice model version 6.0 (Rae et al. 2015), a configuration of the Los Alamos Sea-Ice Model (CICE, Hunke and Lipscomb 2010). The atmosphere is initialised from ERA-Interim (Dee et al. 2011). The ocean and sea-ice are initialised from a $3 D-V A R$ re-analysis using the same NEMOVAR system used to initialise the operational GloSea5 forecasts and hindcasts (Waters et al. 2015).

As mentioned earlier, a concern with GloSea5 is that the strength of the predicted Atlantic sector signal is low compared to observations (Eade et al. 2014). This means that large ensemble sizes are required to identify the signal from the noise which hinders accurate predictions of the associated impacts. We perform the forecasts twice, at different resolutions, to examine whether the higher resolution forecasts give improvement in the strength of the predicted response.

\section{Experimental design and analysis}

Our primary objective in this paper is to isolate the effect of surface re-emergence of ocean temperature anomalies during autumn and winter on surface fluxes, surface air temperature patterns and the atmospheric circulation. A secondary aim is to assess whether model atmospheric resolution influences the predictions. The experimental design is to run an autumn-winter seasonal forecast (September-February) with initial conditions from a historical year (2007) when the subsurface North Atlantic in September was in a neutral state, and compare this with an otherwise identical forecast in which subsurface temperature anomalies are imposed on the oceanic initial state in September below the mixed layer and thus out of direct contact with the atmosphere. Rather than reproduce the conditions of a particular year, the experiment design allows us to isolate and investigate the impact of a subsurface anomaly on a seasonal forecast. The expectation is that the imposed anomalies would not immediately affect the surface ocean and overlying atmosphere, but could do so if and when winter mixing and convection becomes sufficiently deep to mix the anomalies up to the surface. It should be noted that the NAO index remained nearly neutral throughout the autumn and winter of 2007 (NOAA webpage, https://www.cpc.ncep.noaa.gov/products/ precip/CWlink/pna/nao.shtml).

The subsurface temperature perturbation was chosen from a forced ocean simulation for the period 1958-2012 (Blaker et al. 2015). The forced simulation featured a realistic simulation of the North Atlantic temperature field for the period September 2009 to March 2011, including a good representation of the near-surface tripole anomaly, which was forced by the record NAO negative winter of 2009-2010. The procedure was as follows: First, the instantaneous simulated $3 \mathrm{D}$ temperature field corresponding to $00 \mathrm{Z} 1$ September 2010 was output from the forced run. This temperature field was then blended at each model grid point with the initial temperature field used in the control seasonal forecast for 2007. Above $100 \mathrm{~m}$ the control temperature was unchanged, below $180 \mathrm{~m}$ the control temperature was replaced by the temperature of the forced ocean simulation and between 100 and $180 \mathrm{~m}$ a linear combination of the two temperatures was specified. At each point below $100 \mathrm{~m}$, the control salinity was modified in order to maintain the original control density (to machine accuracy) to ensure that the modified initial state would have minimal instantaneous effect on the ocean circulation. The modification of the initial state was confined to the Atlantic basin between the $23^{\circ} \mathrm{S}$ and $65^{\circ} \mathrm{N}$. The difference between the perturbed and control initial state temperatures at $200 \mathrm{~m}$ depth is shown in Fig. 1. The anomaly includes a large area of lower temperatures in the subpolar gyre, which may be related to a weaker AMOC between April 2009 and March 2010 (McCarthy et al. 2012; Cunningham et al. 2013). In general one would expect the
Fig. 1 The difference in the $200 \mathrm{~m}$ temperature $\left({ }^{\circ} \mathrm{C}\right)$ field between the SUBSFC25 and CONTROL25 for the initial conditions. The SUBSFC60 minus CONTROL60 plot is indistinguishable from this

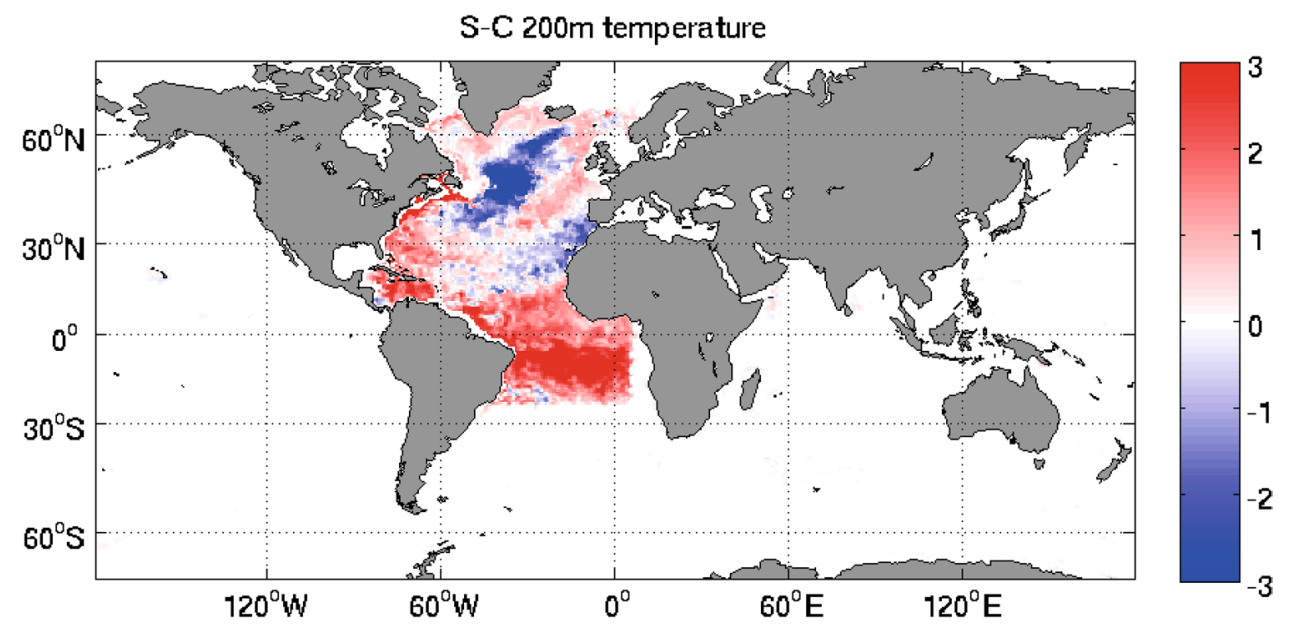


strength of the response to re-emergence to be proportional to the strength of the subsurface anomaly.

Seasonal hindcasts were then run using both the original and modified initial ocean states. It is important to note that apart from the subsurface anomaly, the two ocean states were identical in all other respects. In all, four 50-member ensemble seasonal forecasts were carried out: 2 pairs of control and modified-subsurface forecasts with atmosphere resolutions of $\sim 60 \mathrm{~km}(\mathrm{~N} 216)$ and $\sim 25 \mathrm{~km}(\mathrm{~N} 512)$ respectively, we refer to these experiments as CONTROL60, SUBSFC60, CONTROL25 and SUBSFC25. All simulations had an ocean resolution of $\sim 1 / 4^{\circ}$. Differences between ensemble members are generated by a stochastic physics parameterization, SKEB2 (Bowler et al. 2009).

In order to elucidate the effects of the ocean perturbation, our analysis falls into three sections. First, we compare ensemble means of the SUBSFC simulations to the CONTROL simulations with a focus on surface and subsurface temperatures, surface heat fluxes, surface air temperature (SAT), and mean sea level pressure (SLP). Ensemble mean differences are taken to be significant if they exceed the 99th quantile, which for a normal distribution is 2.58 times the standard error. (The standard error is defined as the square root of $\left(\left(\sigma_{p}^{2} / n_{p}\right)+\left(\sigma_{c}^{2} / n_{c}\right)\right), \sigma$ being the standard deviation of $n$ ensemble members, subscripts $p$ and $\mathrm{c}$ refer to the perturbed and control ensembles, respectively). Due to some data loss, not all 50 ensemble members were available for the analysis. However, for the atmospheric fields (SAT, latent heat flux and SLP) $n$ was between 48 and 50. For the ocean fields (SST, temperature profiles and net heat flux) $n$ was greater than 45 with the exception of CONTROL60 where $n$ was between 20 and 25. Details of the 4 forecast ensembles are in Table 1. In the second section, using a definition of re-emergence based on a deviation of the SST anomaly from the range in the control forecast, the ensemble mean evolution of the re-emergence strength is examined in concert with that of the NAO. Additionally in this section, the range of re-emergence behavior within the ensemble is examined. In particular we calculate the fraction of the total ensemble members that re-emerge within each month. Thirdly, based on this analysis, the atmospheric conditions occurring before, during and after late season re-emergence are examined using an appropriate subset of the ensemble. Because of the smaller size of the subset, significance was calculated using a Monte-Carlo approach detailed in Sect. 4.3.

\section{Results}

\subsection{Ensemble means}

\subsubsection{Ocean response with different atmospheric resolutions}

The evolution of the SUBSFC60 minus CONTROL60 (hereinafter S-C60) SST is shown in Fig. 2. In September there is little difference as the subsurface anomaly in SUBSFC60 remains largely out of contact with the mixed layer. However, as the winter progresses, a marked negative SST anomaly steadily develops along the southeastern flank of the Subpolar Gyre. By January and February the cold SST anomaly is most pronounced with an amplitude of about $2{ }^{\circ} \mathrm{C}$ near $35^{\circ} \mathrm{W}, 50^{\circ} \mathrm{N}$ and with magnitudes more widely of $1{ }^{\circ} \mathrm{C}$ over the region where the initial subsurface anomaly was placed (Fig. 1). There is also evidence of weak positive anomalies developing above the areas where the initial subsurface anomaly was positive. In particular, these regions include the western Subtropical Gyre, the Labrador Sea, the Bay of Biscay and the Rockall Trough. For the higher resolution atmosphere case (SUBSFC25) a very similar development of the SST anomaly occurs (Fig. 3).

Figures 2 and 3 are consistent with SST anomalies developing as the winter mixed layer deepens to the depth of the artificially inserted temperature anomaly in the experiment, the SST decreasing as the cold temperature anomaly is subsequently mixed to the surface. To determine if this is actually the case, the evolution of the SUBSFC and CONTROL temperature profiles areaaveraged in the region of strong temperature anomaly $\left(45.2^{\circ} \mathrm{W}-24.9^{\circ} \mathrm{W}, 43.3^{\circ} \mathrm{N}-53.5^{\circ} \mathrm{N}\right.$, shown by the box in Fig. 2a) are plotted in Fig. 4 (CONTROL60, SUBSFC60) and Fig. 5 (CONTROL25, SUBSFC25). In September, the top $80 \mathrm{~m}$ temperatures for CONTROL (black lines) and

Table 1 List of seasonal forecast experiments and the number of ensemble members, $n$ used to make up the ensemble mean

\begin{tabular}{lllll}
\hline Model run & Atmospheric resolution & $\begin{array}{l}\text { Ensemble size } n \text { in atmospheric fields } \\
\text { [Sep, Oct, Nov, Dec, Jan, Feb] }\end{array}$ & Ocean resolution & $\begin{array}{l}\text { Ensemble size } n \text { in oceanic } \\
\text { fields [Sep, Oct, Nov, Dec, Jan, } \\
\text { Feb] }\end{array}$ \\
\hline CONTROL60 & N216 $(\sim 60 \mathrm{~km})$ & {$[49,49,49,49,49,49]$} & $0.25^{\circ}$ & {$[47,45,46,49,48,48]$} \\
SUBSFC60 & N216 $(\sim 60 \mathrm{~km})$ & {$[48,48,48,48,48,45]$} & $0.25^{\circ}$ & {$[48,48,47,48,4749]$} \\
CONTROL25 & N512 $(\sim 25 \mathrm{~km})$ & {$[48,48,48,48,48,48]$} & $0.25^{\circ}$ & {$[22,23 ., 20,22,25,21]$} \\
SUBSFC25 & N512 $(\sim 25 \mathrm{~km})$ & {$[48,48,48,48,48,48]$} & $0.25^{\circ}$ & {$[50,49,49,48,50,50]$} \\
\hline
\end{tabular}


(a) Sep

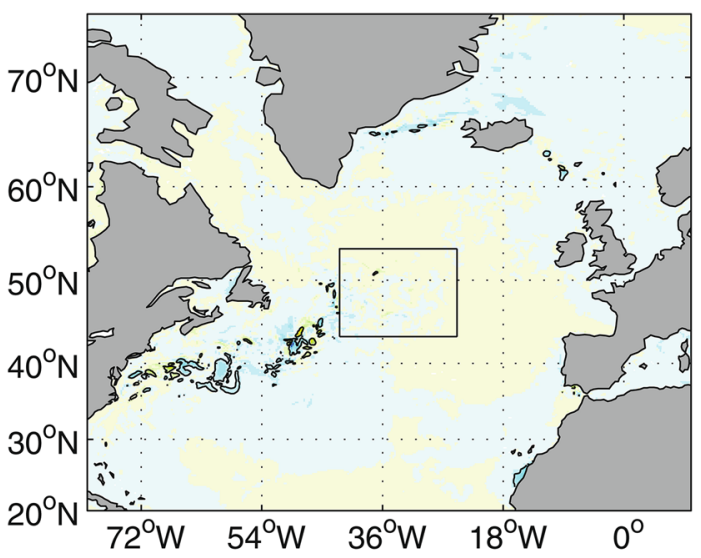

(c) Nov

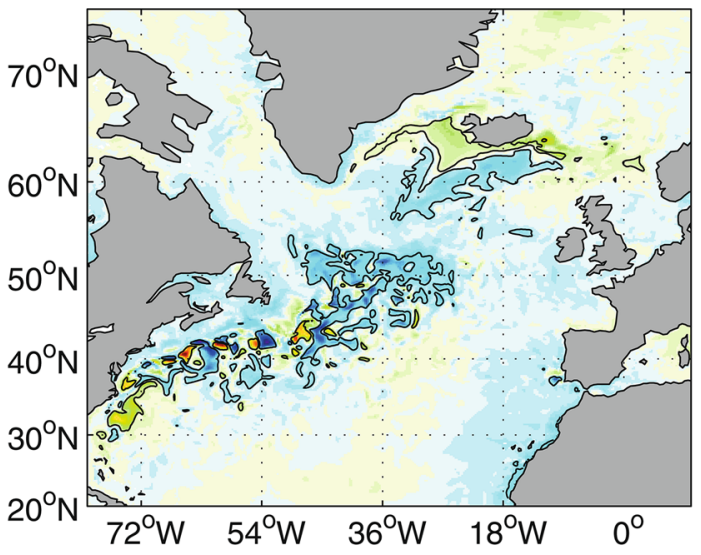

(e) Jan

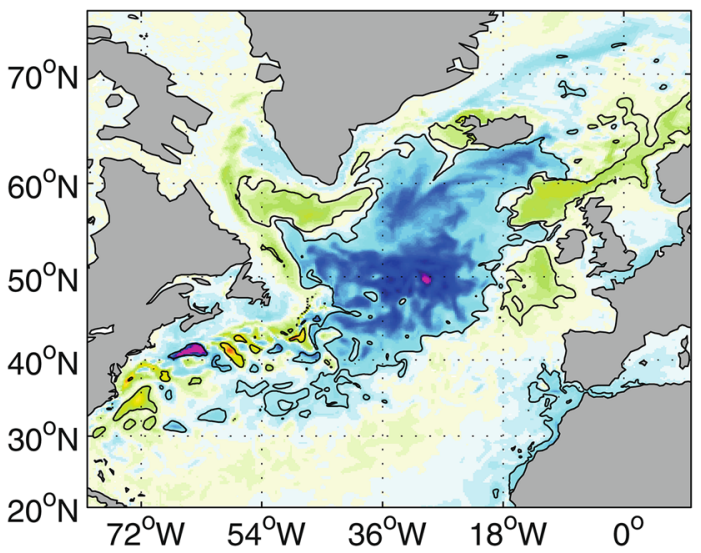

(b) Oct
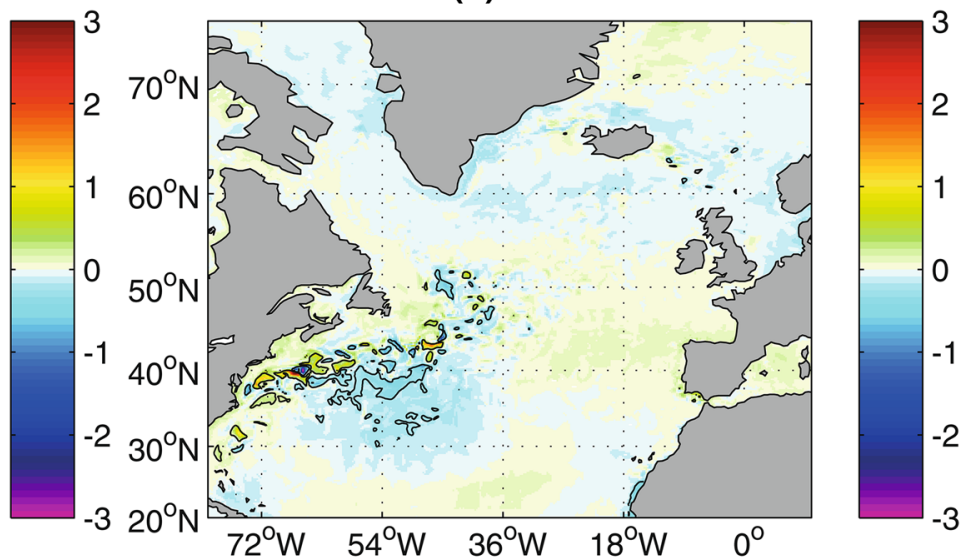

(d) Dec

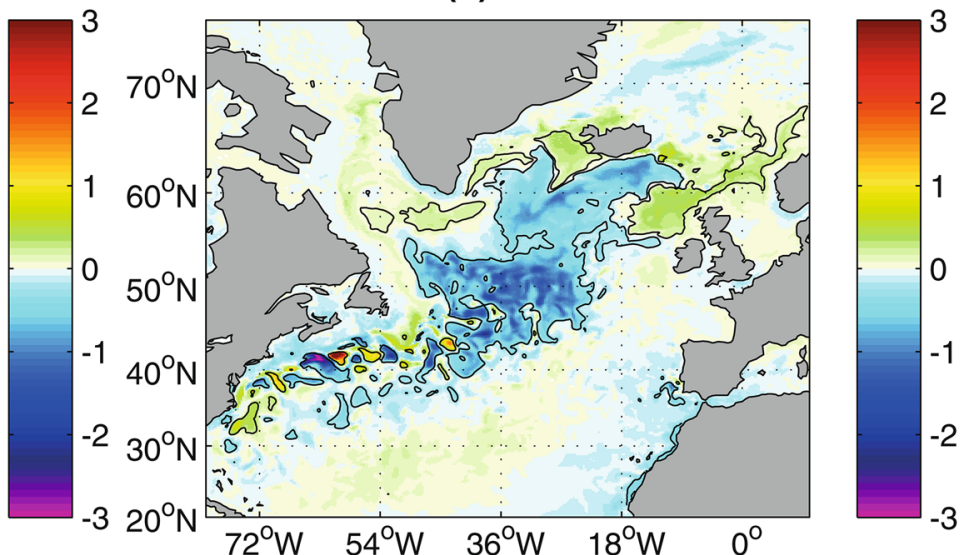

(f) Feb

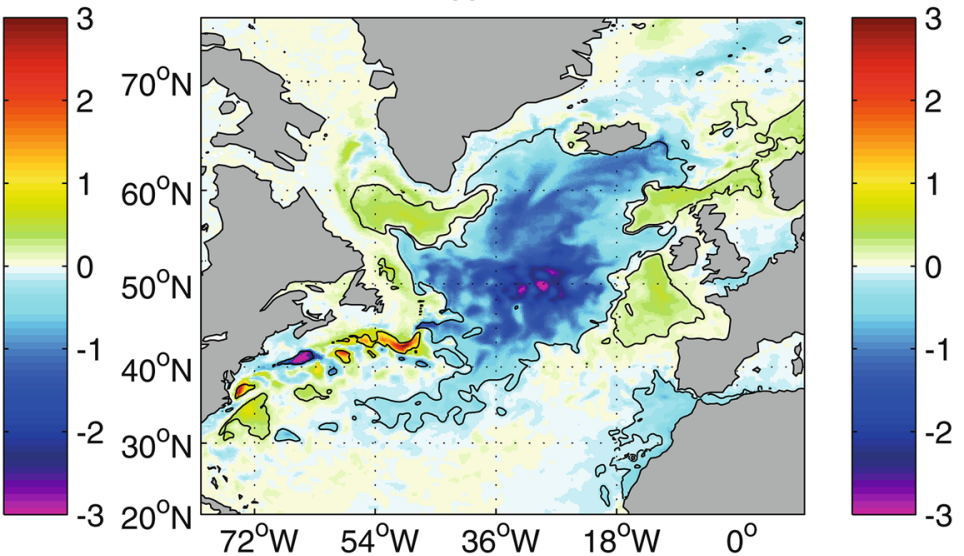

Fig. 2 The S-C60 difference in model SST $\left({ }^{\circ} \mathrm{C}\right)$ for a September, b October, c November, d December, e January and f February. Black contours denote where difference is significant at the $99 \%$ confidence level. The black rectangle in a denotes the re-emergence box referred to in the text

SUBSFC (blue) are very similar whereas between 100 and $700 \mathrm{~m}$ the initial SUBSFC anomaly is evident and intact. However, in the months October through December as the mixed layer deepens to greater than $100 \mathrm{~m}$ the cold anomaly in SUBSFC is reached, and so the temperature of the mixed layer (and surface) begins to reduce and a gap opens up between the CONTROL and SUBSFC ensemble at the surface. In January and February the mixed layer continues to deepen into a depth range where the difference between the SUBSFC and CONTROL is greater. As a consequence there is a further reduction in the SST anomaly during these months. The evolution of the temperature profiles with the high-resolution atmosphere (SUBSFC25) are very similar (Fig. 5). The evolution of the profiles in Figs. 4 
(a) Sep

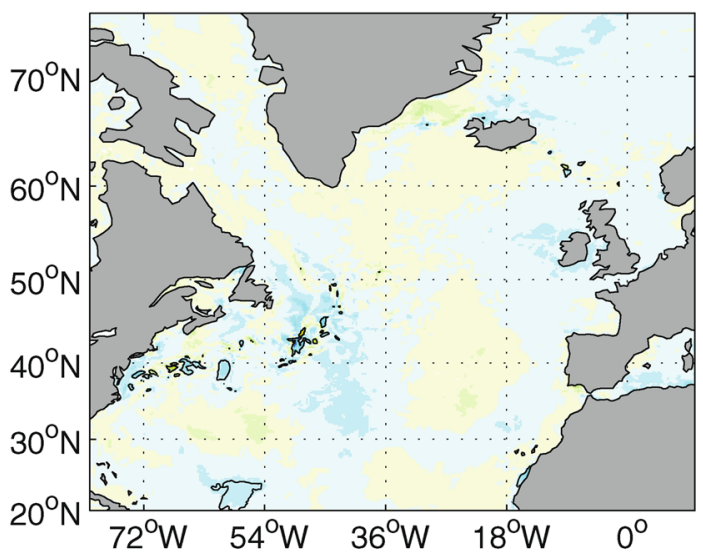

(c) $\mathrm{Nov}$

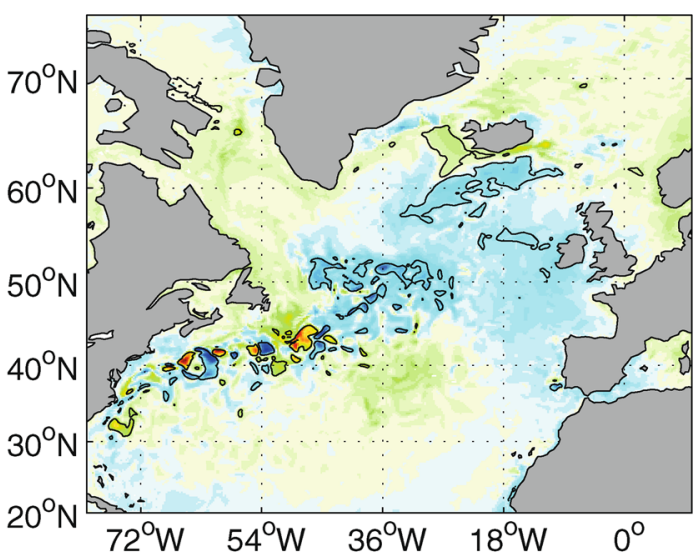

(e) Jan

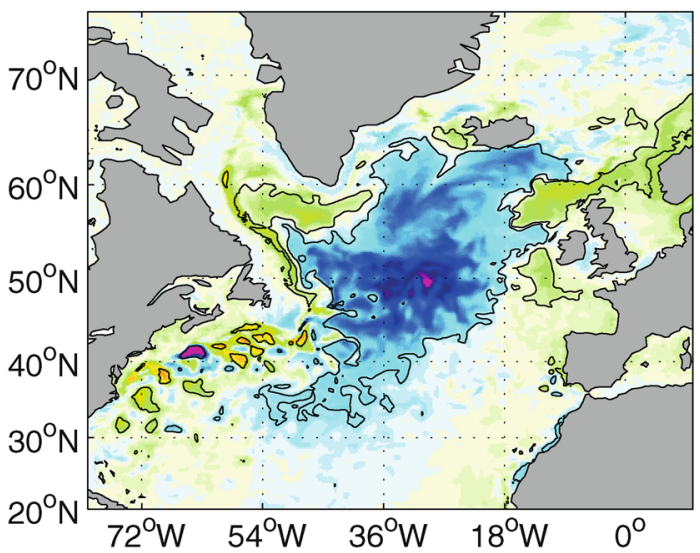

(b) Oct
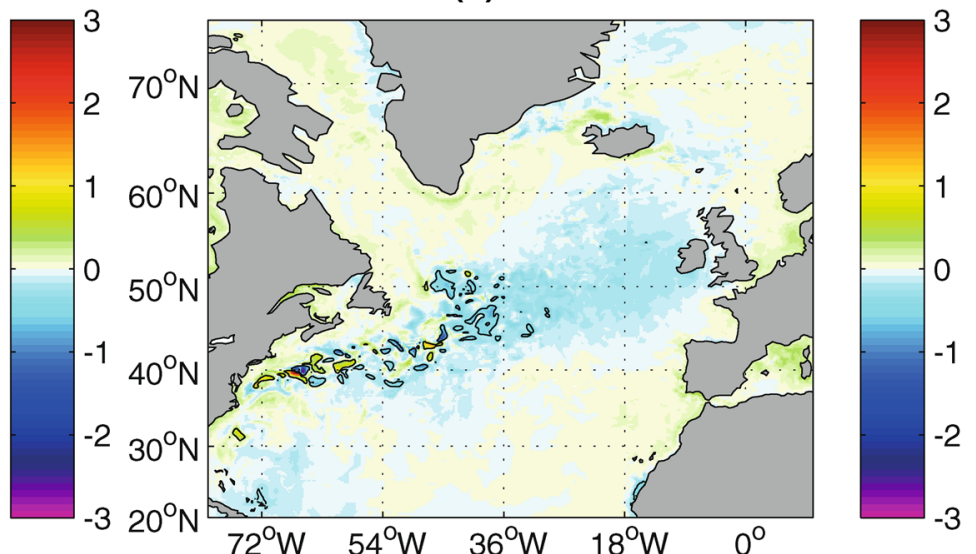

(d) $\mathrm{Dec}$

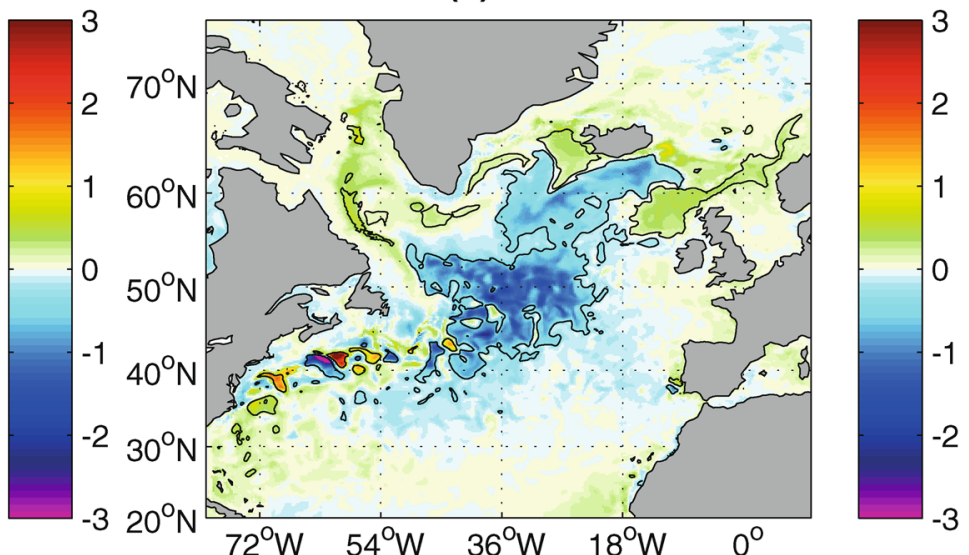

(f) Feb

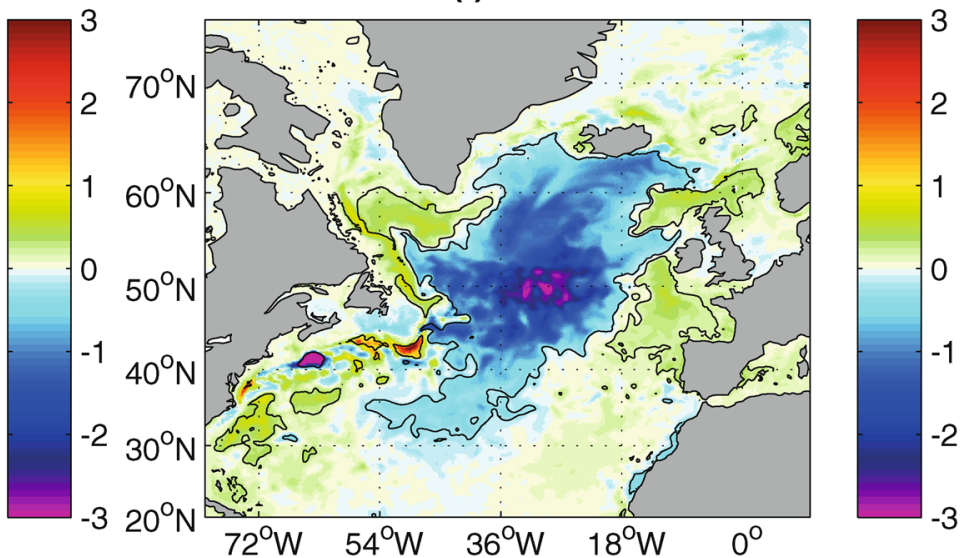

Fig. 3 The S-C25 difference in model SST $\left({ }^{\circ} \mathrm{C}\right)$ for a September, b October, c November, d December, e January and f February. Black contours denote where difference is significant at the $99 \%$ confidence level

and 5 confirms that a winter mixed layer is developing in both the experiment and control runs. However, the mixed layers in the SUBSFC experiments meet the anomalously cold water which subsequently mixes to the surface, lowering the SST. It is thus confirmed that the SST anomalies in Figs. 2 and 3 are associated with the re-emergence of a subsurface temperature anomaly.

\subsubsection{Response of net heat flux to SST anomalies}

The net surface heat flux is made up of four components; net shortwave, net longwave, latent heat and sensible heat. They are defined as being positive into the ocean. Longwave, latent heat and sensible heat are the terms directly affected by SST, with a decrease in SST associated with 
Fig. 4 The area-averaged temperature profiles for the re-emergence region (rectangle in Fig. 2a) for a September, $\mathbf{b}$ October, c November, $\mathbf{d}$ December, e January and f February of the SUBSFC60 experiment (blue line) and CONTROL60 (black line). Thin grey lines denote where difference is significant at the $99 \%$ confidence level 99\% significance. Blue and black dots denote the mixed layer depth based on a $0.2^{\circ} \mathrm{C}$ difference from the surface temperature for SUBSFC60 and CONTROL60 respectively (a) Sep

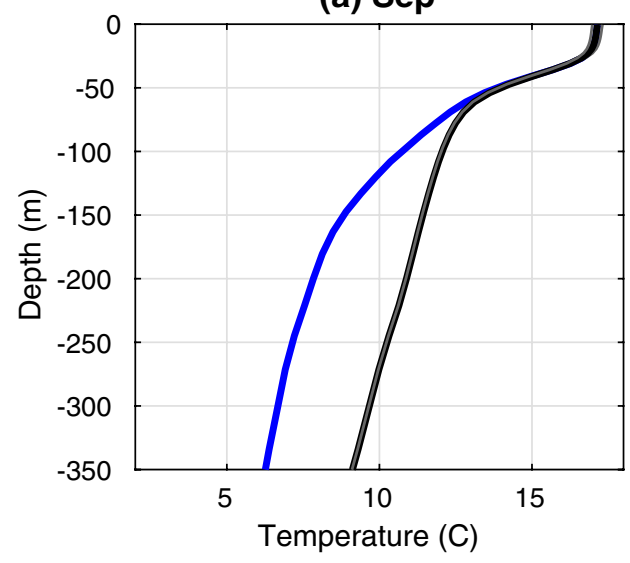

(c) Nov

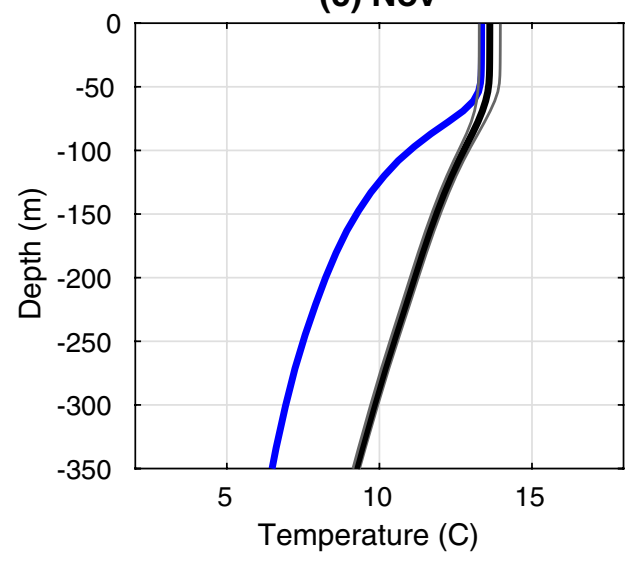

(e) Jan

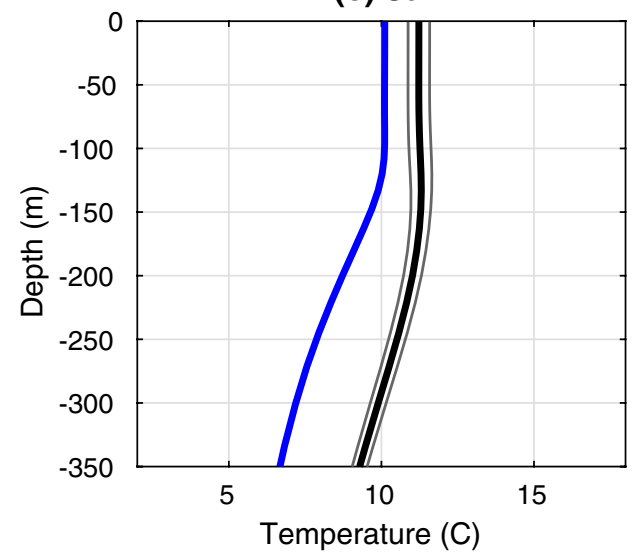

(b) Oct

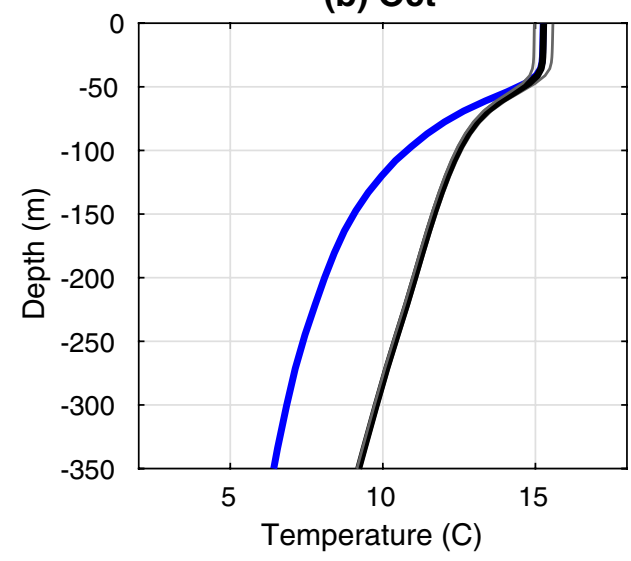

(d) Dec

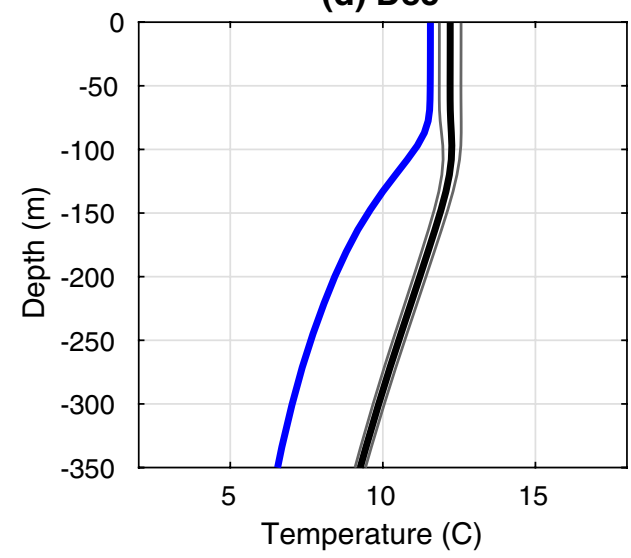

(f) Feb

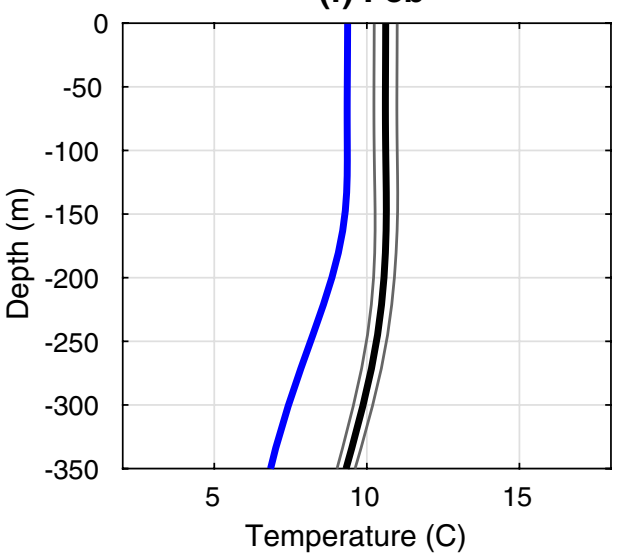

decrease in oceanic heat loss in all terms especially the turbulent fluxes (latent and sensible heat). Consequently, in the absence of other large effects it is expected that the reemerging negative SST anomalies in Figs. 2 and 3 will be associated with a reduction in oceanic heat loss to the atmosphere. This is confirmed in Figs. 6 and 7 which show the evolution of the S-C60 and S-C25 net heat flux anomaly for September through February over the region where the cold SST anomaly develops (Fig. 3). Much like the negative SST anomaly, a significant positive net heat flux anomaly is seen to develop over the Subpolar Gyre in January and February.

The differences in response between the two resolutions in January and February anomalies are shown in Fig. 8. While in January SUBSFC25 has more heat loss north of $50^{\circ} \mathrm{N}$ and less heat loss in the western basin south of $50^{\circ} \mathrm{N}$, these differences are not significant. In the case of February, when the SST anomaly is most developed, the difference, of up to $50 \mathrm{~W} \mathrm{~m}^{-2}$ is significant (Fig. 8b). In the region of significant difference, to the south of Iceland the sign of the 
Fig. 5 The area-averaged temperature profiles for the re-emergence region (rectangle in Fig. 2a) for a September, $\mathbf{b}$ October, c November, d December, e January and $\mathbf{f}$ February of the SUBSFC25 experiment (blue line) and CONTROL25 (black line). Thin grey lines denote where difference is significant at the $99 \%$ confidence level. Blue and black dots denote the mixed layer depth based on a $0.2^{\circ} \mathrm{C}$ difference from the surface temperature for SUBSFC25 and CONTROL25 respectively (a) Sep

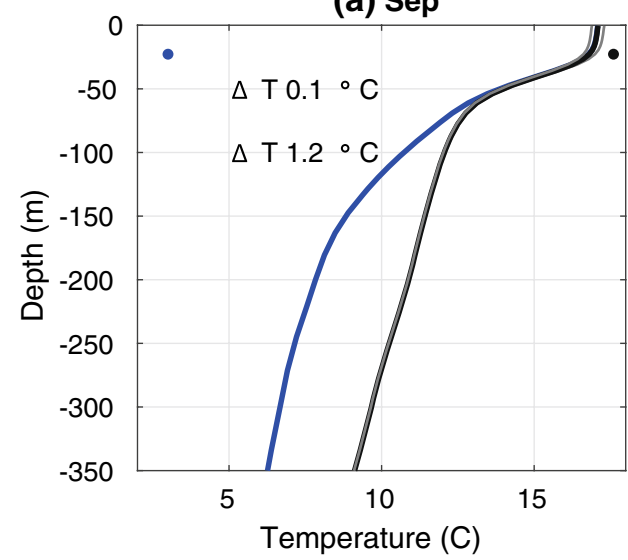

(c) Nov

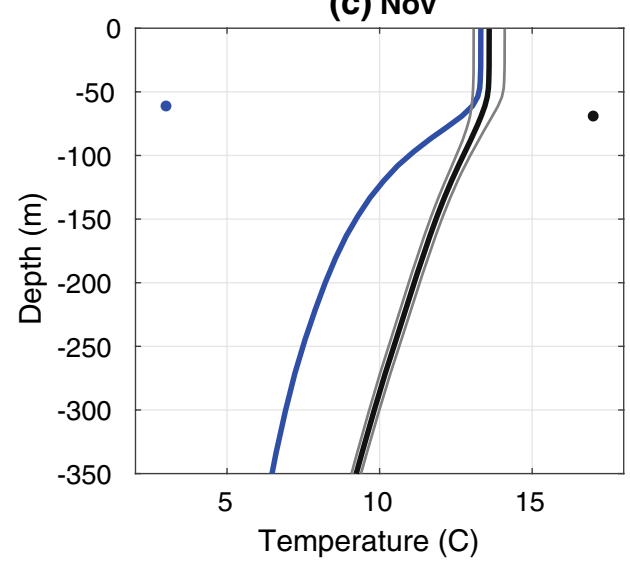

(e) Jan

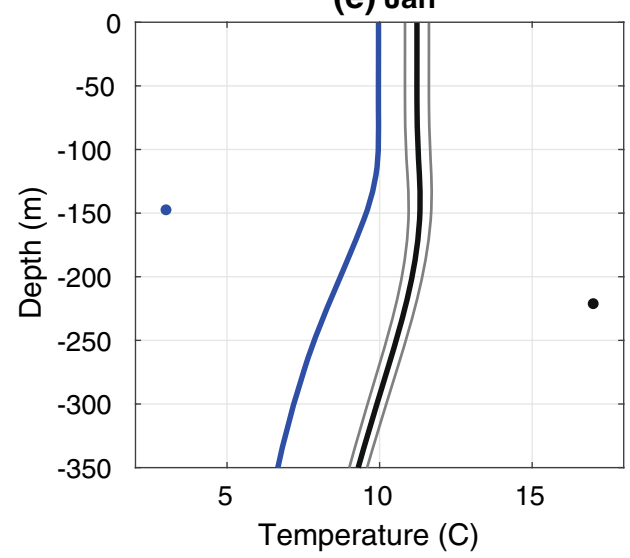

(b) Oct

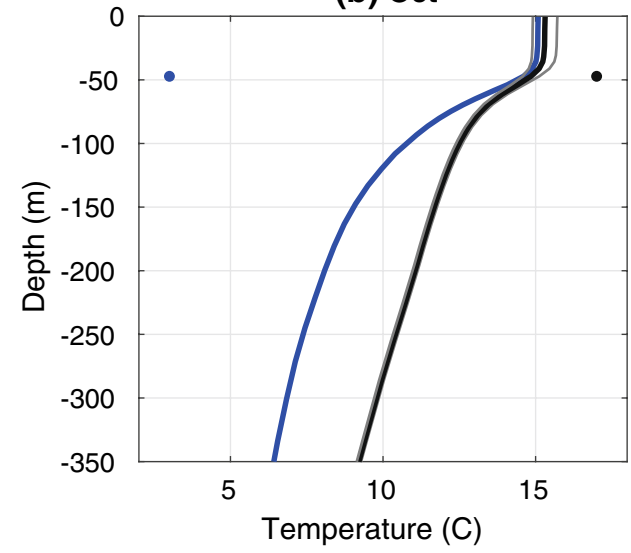

(d) Dec

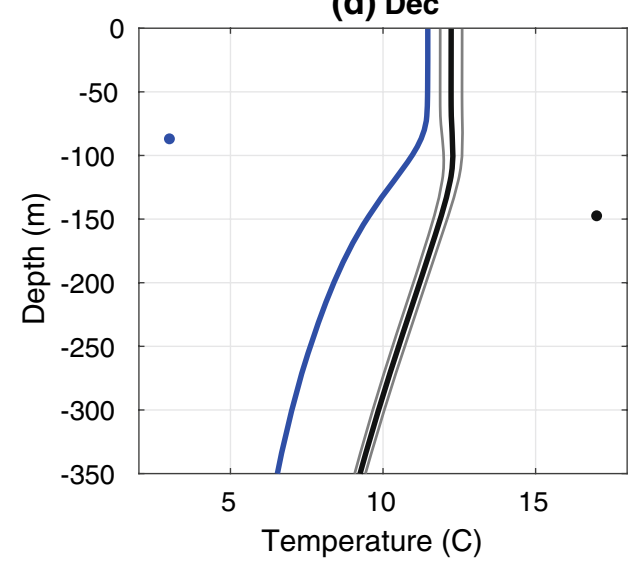

(f) Feb

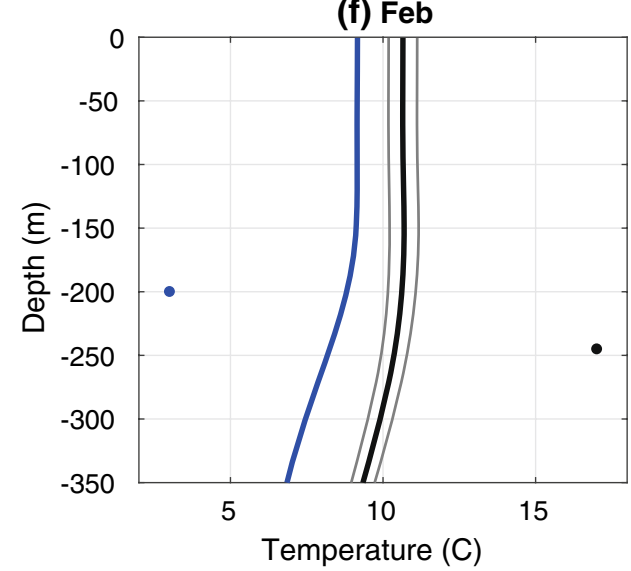

difference indicates that re-emergence in SUBSFC25 results in a significantly greater suppression of the heat loss to the atmosphere than in SUBSFC60.

To summarize: as the winter mixed layer deepens, the SUBSFC experiments successfully simulate the re-emergence of a sub-surface temperature anomaly. The resulting negative SST anomaly leads to a reduction in ocean heat loss. Although there are strong similarities in the response of the ocean temperature field in the SUBSFC60 and SUBSFC25 versions of the model, there is a significantly greater (i.e. $50 \mathrm{~W} \mathrm{~m}^{-2}$ ) response in the surface net heat flux found in February of the higher resolution version (N512) of GloSea5. Because of its stronger net heat flux response, in the next section we focus on the N512 version of the model to examine changes in the surface atmospheric conditions. 
(a) Sep

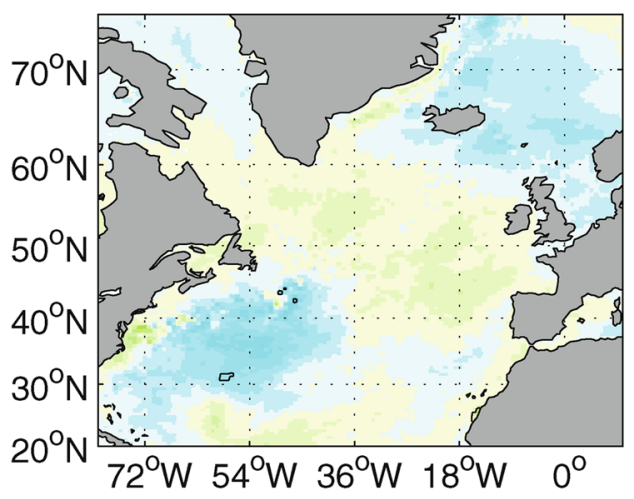

(c) Nov

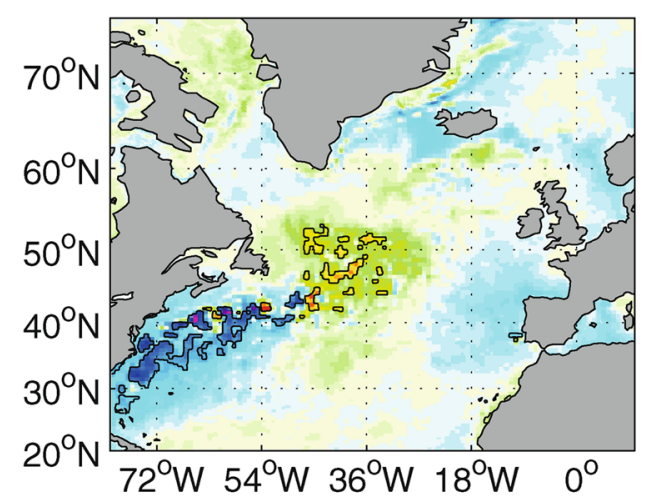

(e) Jan

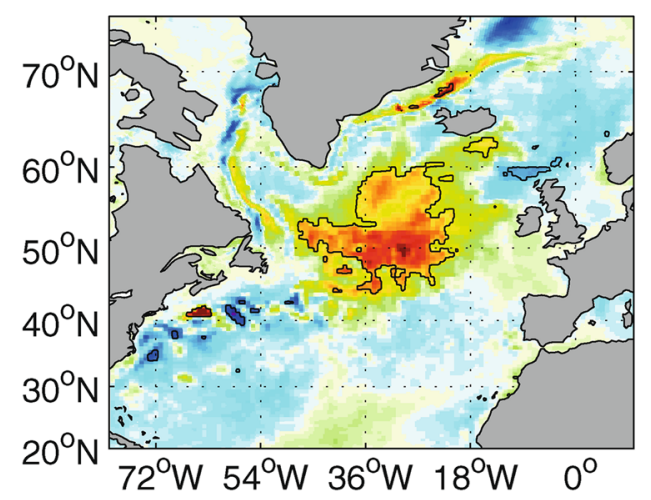

(b) Oct
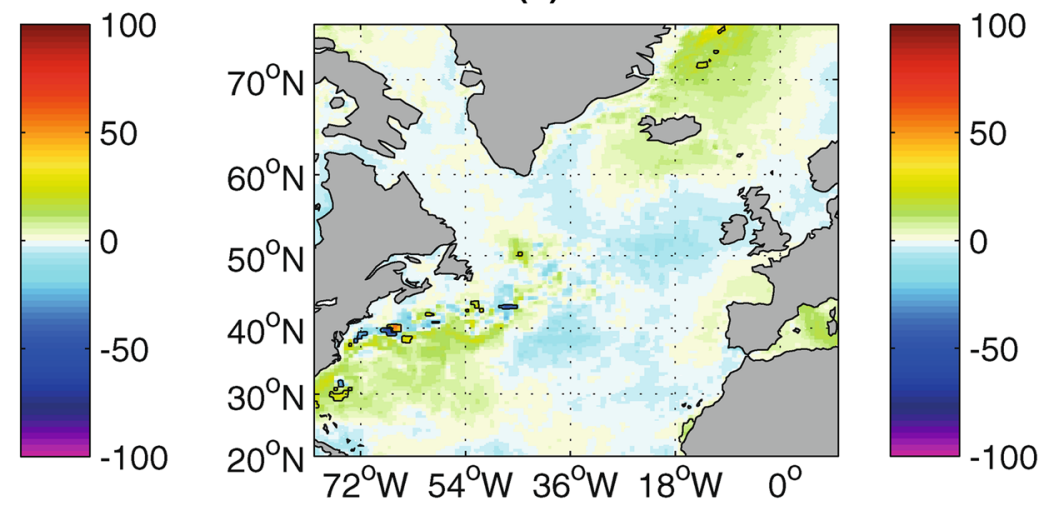

(d) Dec
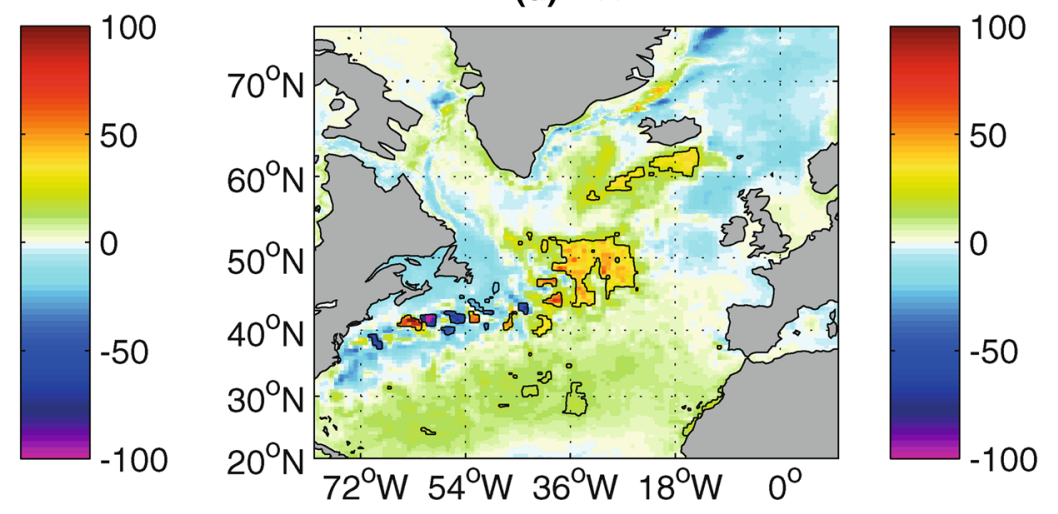

(f) Feb
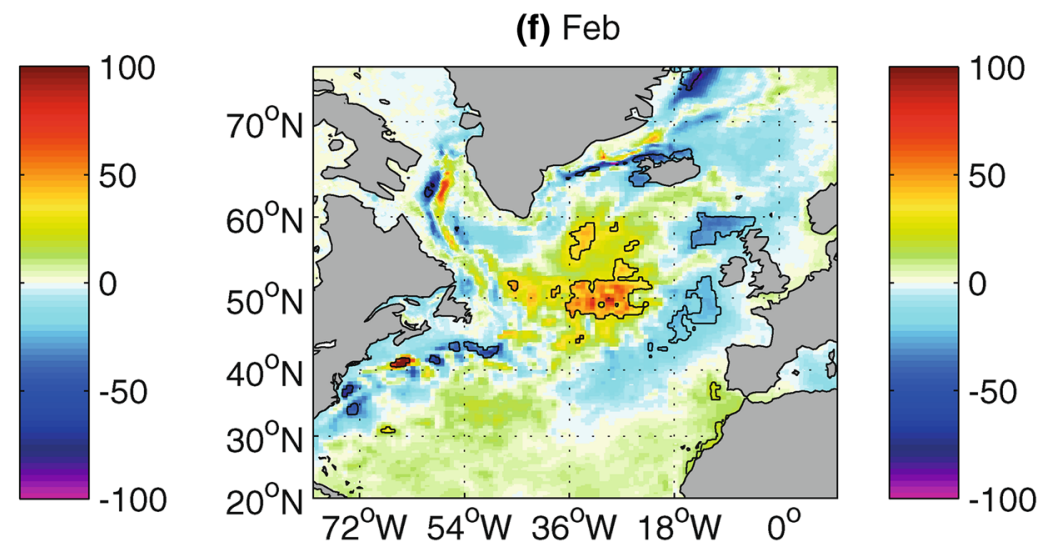

Fig. 6 The S-C60 difference in model net heat flux $\left(\mathrm{W} \mathrm{m}^{-2}\right)$ for a September, b October, $\mathbf{c}$ November, $\mathbf{d}$ December, e January and $\mathbf{f}$ February. Black contours denote where difference is significant at the $99 \%$ confidence level. Heat flux is positive into the ocean

\subsubsection{Development of anomalous atmospheric conditions}

Having established that the change in SST and net heat flux associated with the perturbed run SUBSFC25 is due to the successful simulation of re-emergence, we now examine if this brings any significant change to the overlying atmosphere. The evolution of the S-C25 surface air temperature (SAT) anomaly is shown in Fig. 9. It is evident that a cold SAT anomaly develops over the region where the SST anomaly develops. Small areas of the SPG cold SAT anomaly first become significant in October, with the area becoming larger and the anomaly strengthening in subsequent months until it is greater than $2{ }^{\circ} \mathrm{C}$ through January and February. The areas of significant anomaly extend very little over land (there is a small area with a significant anomaly over Europe in December and a number of small areas over North Africa in November, December and February). 
(a) Sep

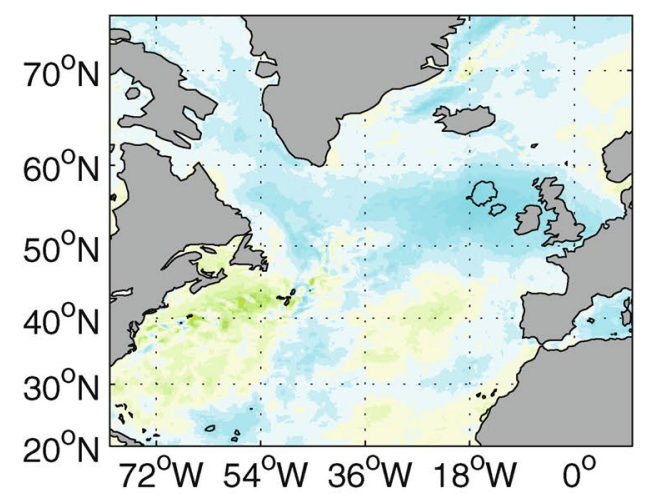

(c) Nov

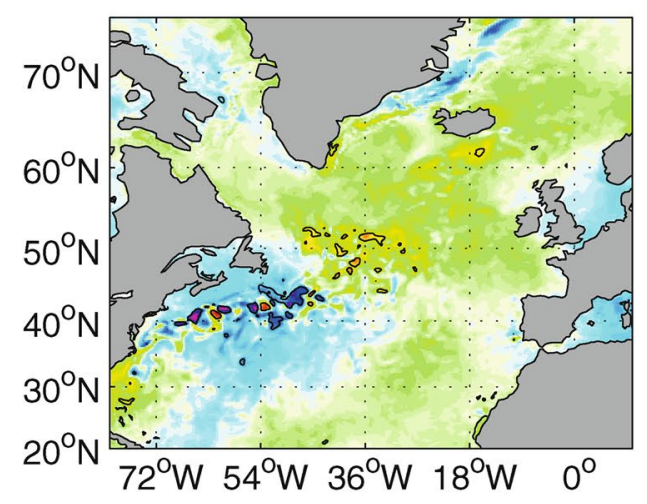

(e) Jan

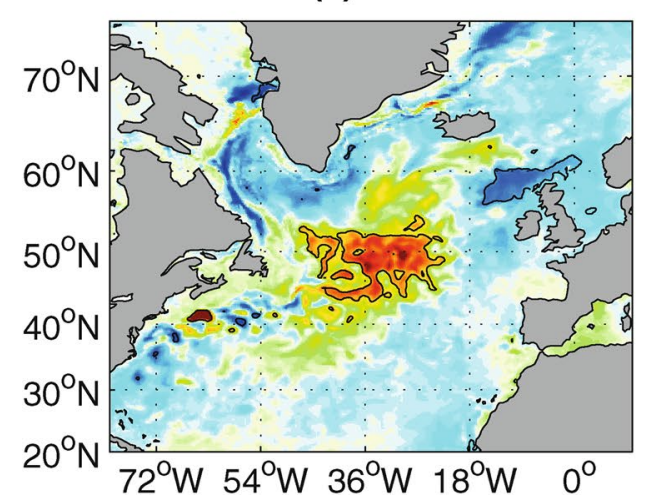

(b) Oct
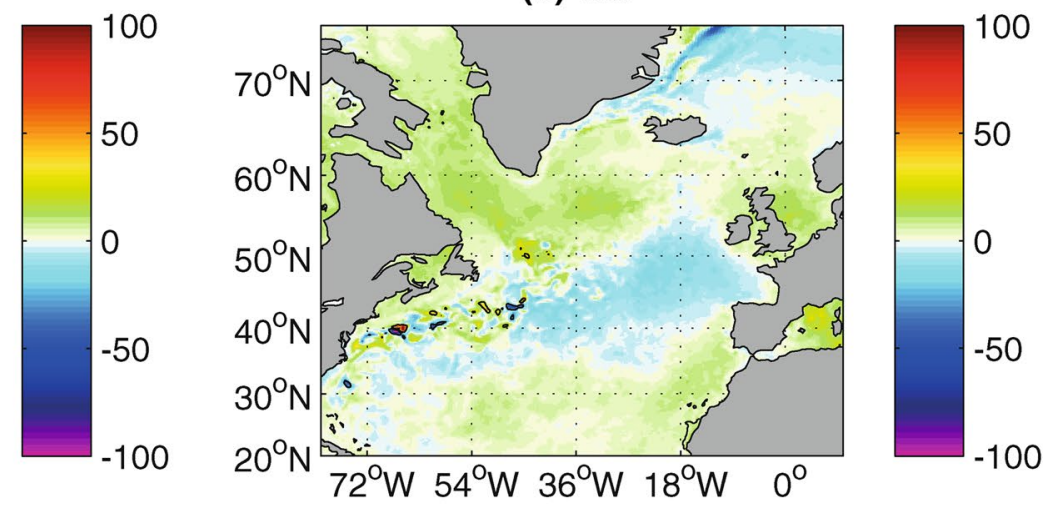

(d) Dec

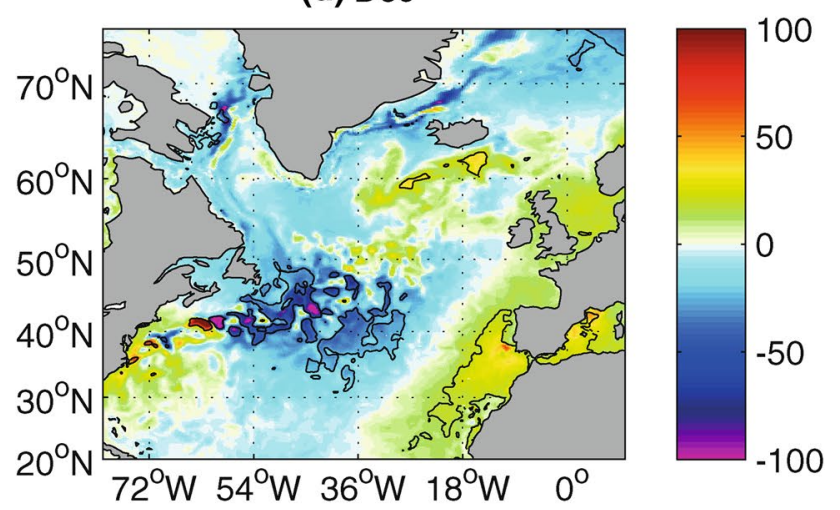

(f) Feb

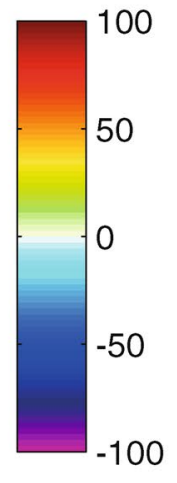

100

50

$-50$

$-100$

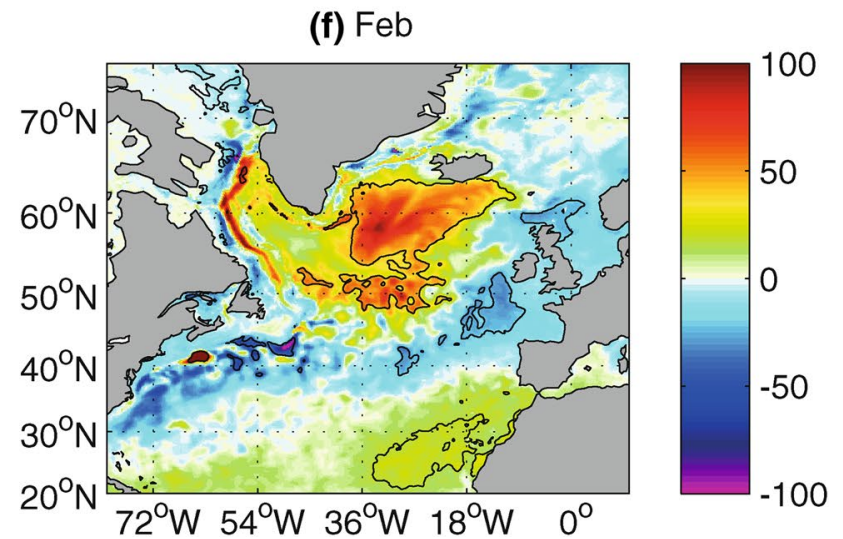

Fig. 7 The S-C25 difference in model net heat flux $\left(\mathrm{W} \mathrm{m}^{-2}\right)$ for a September, $\mathbf{b}$ October, $\mathbf{c}$ November, $\mathbf{d}$ December, $\mathbf{e}$ January and $\mathbf{f}$ February. Black contours denote where difference is significant at the $99 \%$ confidence level. Heat flux is positive into the ocean

With regard to the S-C25 SLP difference shown in Fig. 10, for September through January the difference is weak ( 3 to $6 \mathrm{hPa})$ and not significant. In February, when the SST anomaly is most developed, a significant low pressure anomaly develops over the subtropical gyre, indicative of a negative NAO response. The strong and unambiguous response in February SLP in the higher resolution forecast contrasts with the insignificant effect in the lower resolution case (not shown). This greater signal in the SUBSFC25 February atmospheric circulation may be associated with the stronger heat flux anomaly relative to SUBSFC60 (Fig. 8b).

Summarizing Figs. 9 and 10, the evidence of the S-C25 ensemble means is that in the region of the negative SST anomaly, the re-emergence is associated with a significant reduction in SAT but that there is no clear response of the atmospheric circulation as depicted by the SLP until late 
(a) Jan Net Heat

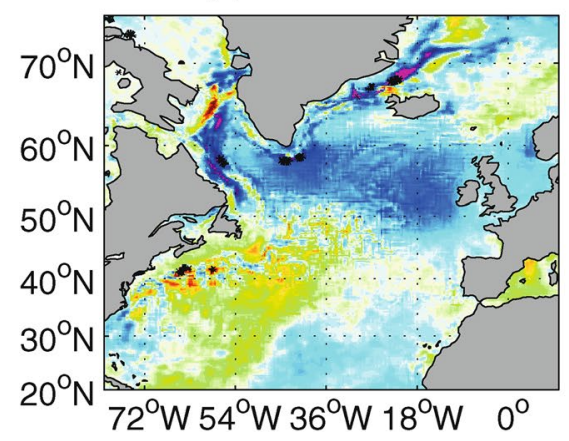

(b) Feb Net Heat

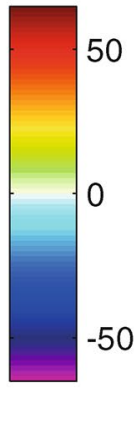

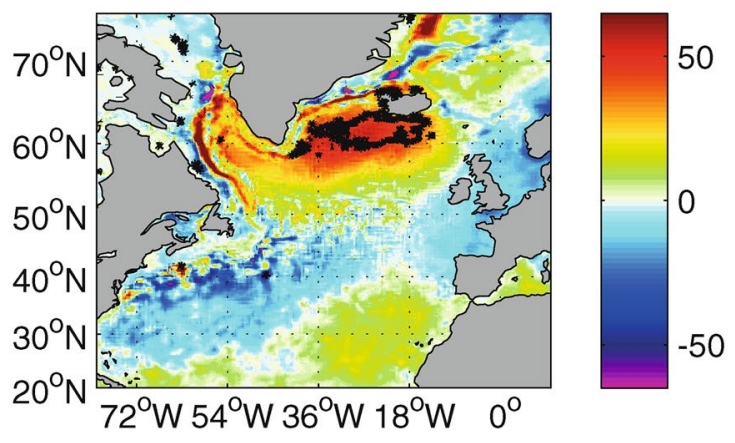

Fig. 8 Difference between S-C25 and S-C60 net heat flux $\left(\mathrm{W} \mathrm{m}^{-2}\right)$. For a January and b February. Black contours denote where difference is significant at the $99 \%$ confidence level. Heat flux is positive into the ocean

winter. In the next section, the evolution of the SLP index, the NAO will be examined, in the context of the timing of reemergence in the experiment.

\subsection{The NAO and the timing and extent of re-emergence in the perturbed ensemble}

Until now the impact of the re-emerging SST anomaly on the coupled ocean-atmosphere system has been isolated by examining the difference in the SUBSFC and CONTROL ensemble means. However, within the ensembles there is a considerable range of responses. To quantify this different behaviour, we first define a measure of re-emergence, $\mathrm{R}$ (for each month) applicable to each ensemble member by taking the area average temperature in a box covering the region of the ocean surface where re-emergence occurs $\left(43.3^{\circ}-53.3^{\circ} \mathrm{N}\right.$, $45.2^{\circ}-24.9^{\circ} \mathrm{W}$, the region marked as black rectangle in Fig. $\left.2 \mathrm{a}\right)$ and subtracting the CONTROL ensemble mean area average temperature:

$R(n, l)=\frac{1}{A}\left\{\int_{y_{1}}^{y_{2}} \int_{x_{1}}^{x_{2}} \theta_{S}^{n}(x, y, l) d x d y-\frac{1}{N} \sum_{i=1}^{N} \int_{y_{1}}^{y_{2}} \int_{x_{1}}^{x_{2}} \theta_{C}^{i}(x, y, l) d x d y\right\}$

where $R(n, l)$ is the re-emergence index for ensemble member $n$ and month $l(l \in\{$ sep, oct, nov, dec, jan, feb $\}) ; \theta_{S}^{n}(x, y, l)$ is the SST for simulation $S$ (SUBSFC) ensemble member $n$ for month $l ; \theta_{C}^{i}(x, y, l)$ is the SST for CONTROL ensemble member $i$ for month $l ; x$ and $y$ are the longitude and latitude respectively; and the limits of integration are $\left(x_{1}\right.$, $\left.x_{2}\right)=\left(-43.3^{\circ} \mathrm{W},-24.9^{\circ} \mathrm{W}\right)$ and $\left(y_{1}, y_{2}\right)=\left(43.3^{\circ} \mathrm{N}, 53.3^{\circ} \mathrm{N}\right)$. $N$ is the total number of ensemble members and

$A=\int_{y_{1}}^{y_{2}} \int_{x_{1}}^{x_{2}} d x d y$ is the area of the region over which the integration is performed. $R$ can be defined for ensemble members from experiments SUBSFC25, CONTROL25, SUBSFC60 and CONTROL 60 by subtracting the appropriate ensemble mean area average control SST in each case.

We regard a member $n$ of the SUBSFC ensembles as having reemerged in any particular month $l$, if $R(n, l)<R$ threshold $=-0.9{ }^{\circ} \mathrm{C}$. The value of $R_{\text {threshold }}$ is chosen as the most negative individual value $R(n, l)$ that we found in the CONTROL60 and CONTROL25 ensembles, so the SUBSFC ensembles are only considered to have reemerged if their re-emergence indices are more negative than the lowest values observed in the CONTROL ensembles.

The fraction of the ensemble members simulating reemergence in each month, for both SUBSFC25 and SUBSFC60 experiments is shown in Fig. 11a. Based on this measure, the higher resolution atmosphere is slightly more efficient in simulating re-emergence. This is consistent with Hewitt et al. (2016) who found a higher resolution version of the HadGEM3 increased mixed layer depth in our reemergence region. In terms of the SUBSFC25 experiment, the fraction of ensemble members displaying re-emergence increases from 2\% in October to 90\% in February. It is noted that in November and December, less than 20\% and 45\% respectively of ensemble members have re-emerged. As a point of reference, observed re-emergence near the region of interest displays peak pattern correlations in November (e.g. Cassou et al. 2007). This implies that although there is some spread in the time of re-emergence, most of the reemergence in the experiment is simulated later than typically observed.

In Fig. $11 \mathrm{~b}$ we show the ensemble mean NAO response as a function of time in the two seasonal forecasts-red for high resolution (SUBSFC25) and green for low (SUBSFC60)and compare with the observed differences between the NAO index in 2010 compared to 2007. Although there are likely many factors contributing to the NAO difference 
(a) Sep

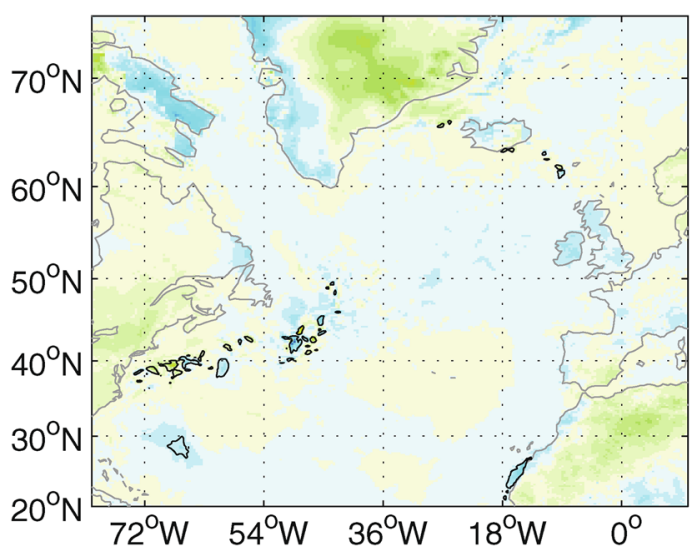

(c) Nov

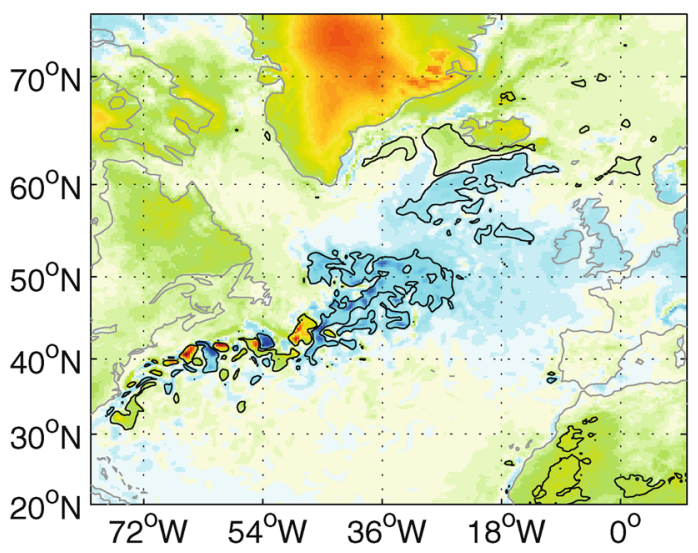

(e) Jan

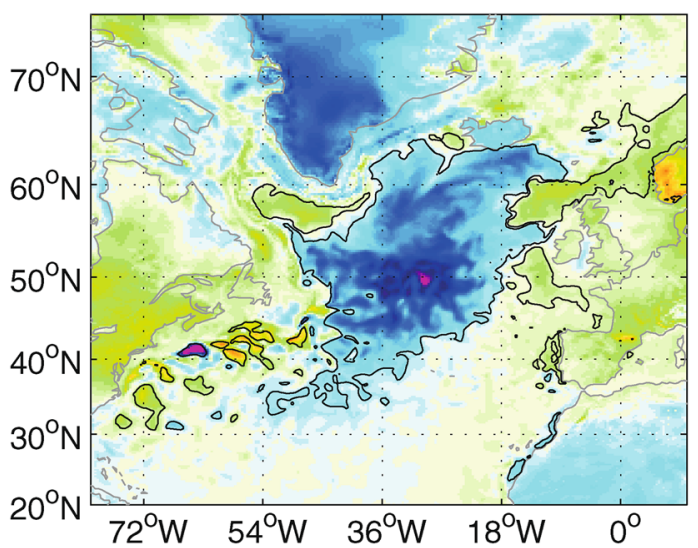

(b) Oct
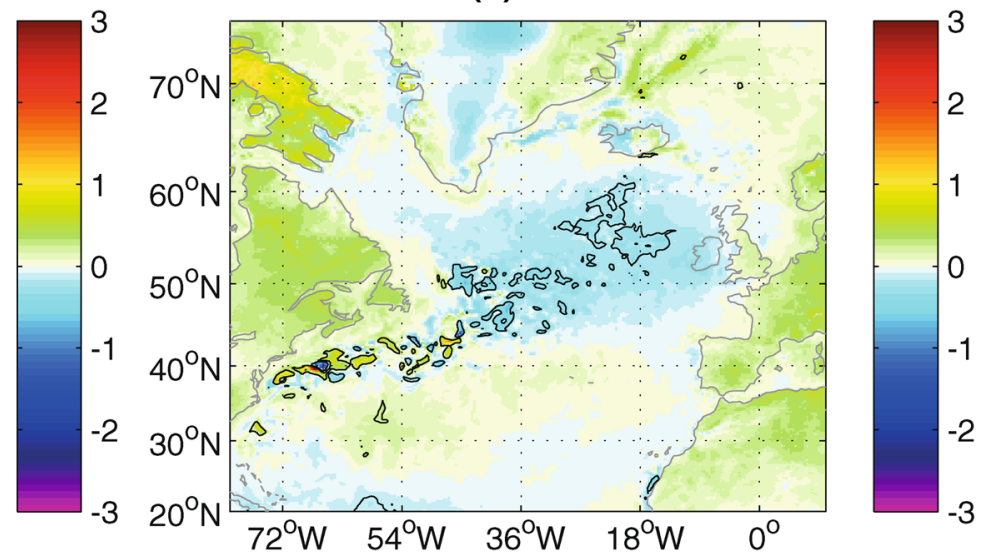

(d) Dec
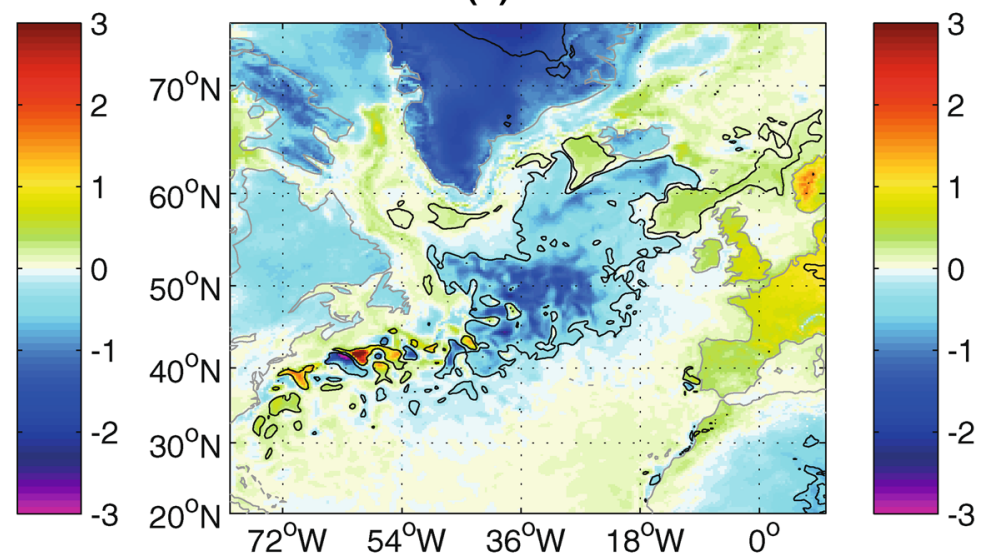

(f) Feb
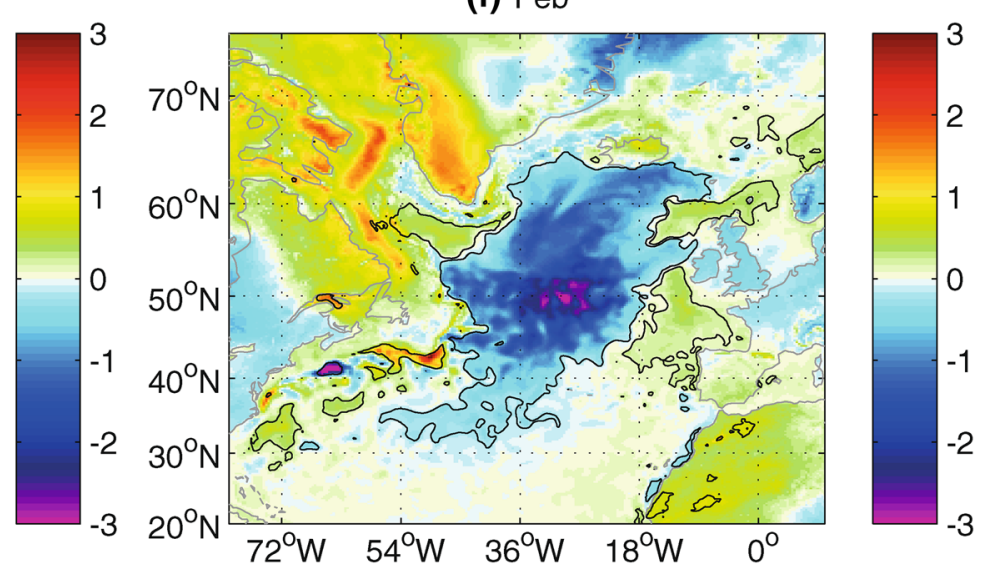

Fig. 9 The S-C25 difference in SAT $\left({ }^{\circ} \mathrm{C}\right)$ for a September, b October, c November, d December, e January and f February. Black contours denote where difference is significant at the $99 \%$ confidence level

between 2010-2011 and 2007-2008, it has been shown that the 2010 shift towards a negative NAO was mainly associated with re-emerging SSTs (Maidens et al. 2013; Buchan et al. 2014). The dashed lines on the forecasts show the $95 \%$ confidence limits on the ensemble means. These show that the $60 \mathrm{~km}$ atmosphere has no significant NAO response throughout the winter, whereas the $25 \mathrm{~km}$ atmosphere shows a significant negative shift in February suggesting that reemergence forces an atmospheric response in this case. We note that the size of the shift is small compared to the difference between the observed NAO index between December 2010 and December 2007. Figure 11b also highlights the fact that the NAO response occurs much later in the season in the forecasts compared to that in observations. 
(a) Sep

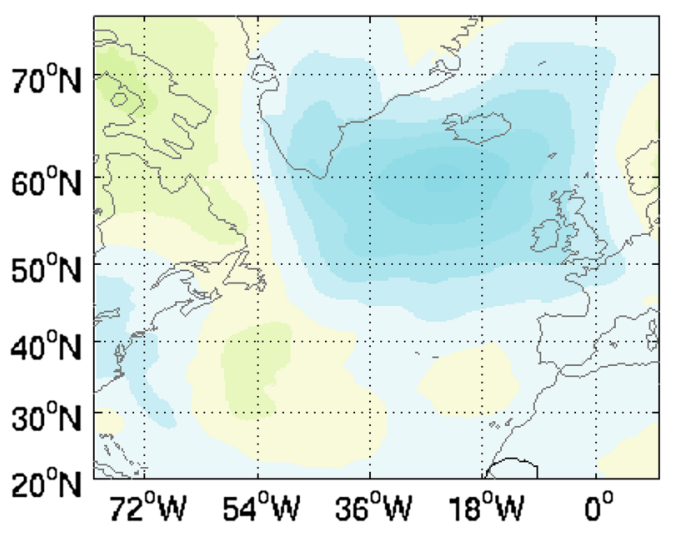

(c) Nov

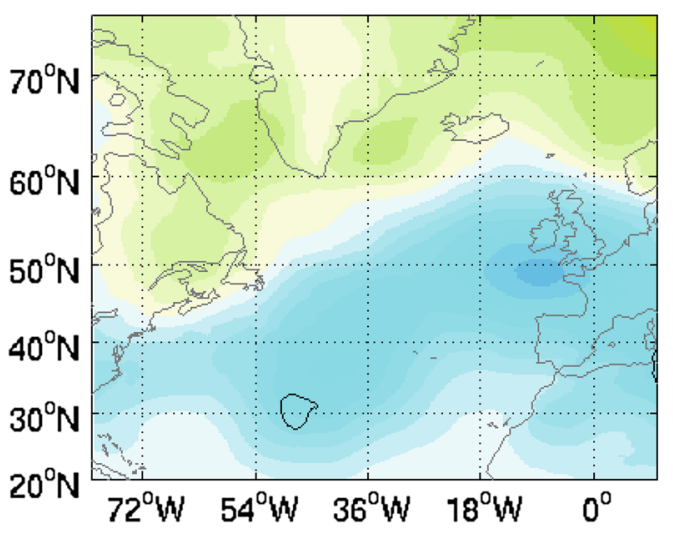

(e) Jan

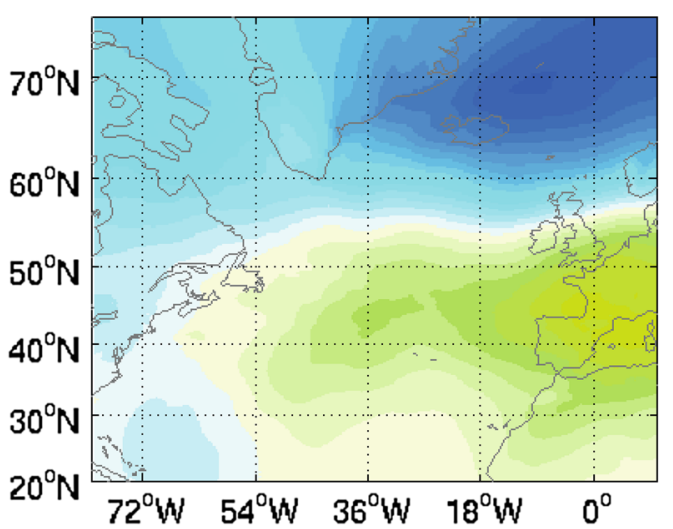

(b) Oct
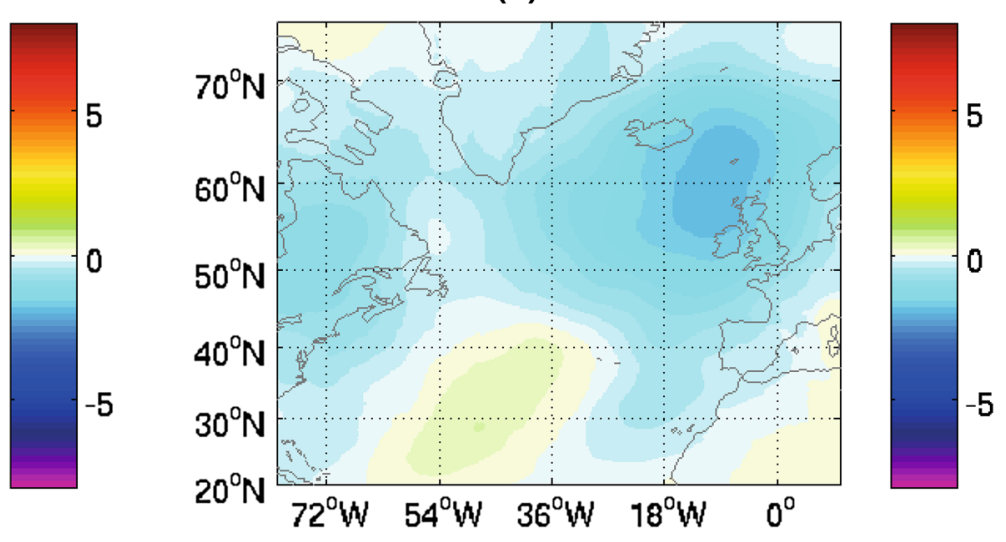

(d) Dec
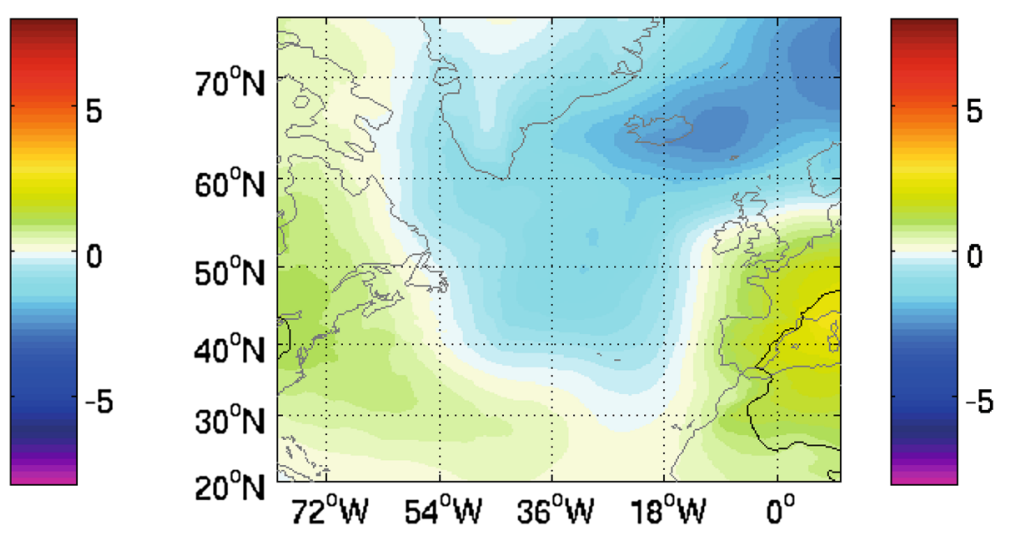

(f) Feb
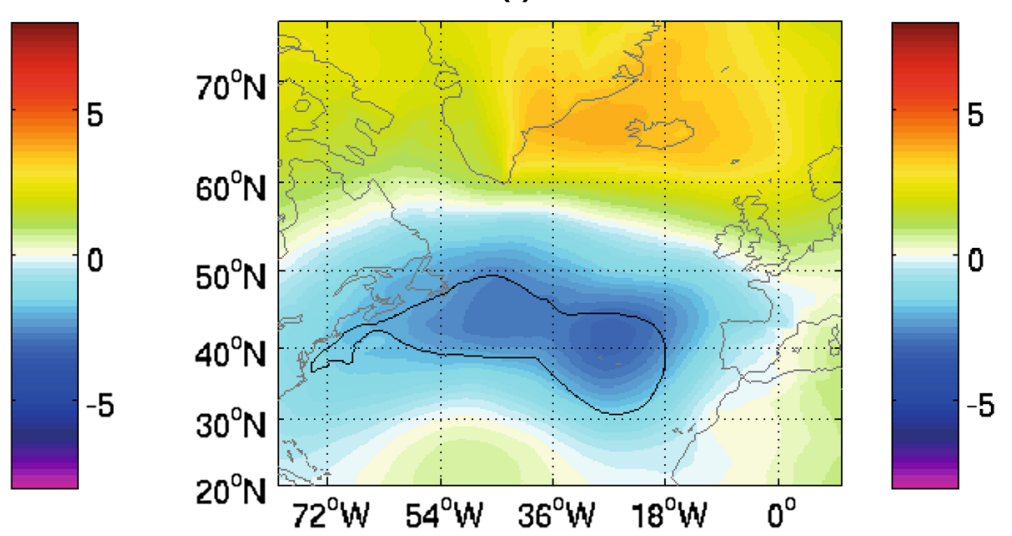

Fig. 10 The S-C25 difference in SLP (hPa) for a September, b October, c November, d December, e January and f February. Black contours denote where difference is significant at the $99 \%$ confidence level

The reason for this is likely related to the late re-emergence in the forecasts. Figure 11c shows corresponding ensemble mean SST anomalies for the two resolutions in our re-emergence box (i.e. the re-emergence index, $R$, defined above, Eq. 1) and the observed SST difference between 2010 and 2007. We see in Fig. 11c that in reality, between September and November in 2010, reemerged SST anomalies were already present, around $-1.2 \mathrm{~K}$ relative to 2007 , well above our re-emergence threshold of $-0.9 \mathrm{~K}$, with a strongly negative NAO index occurring in December 2010. By contrast in the forecast experiments, reemerged SST anomalies of comparable size did not appear until mid-December. A caveat here is that although the observed re-emergence in 2010 has been previously documented (Taws et al. 2011), 
Fig. 11 a Fraction of the ensemble members in SUBSFC60 (white bars) and SUBSFC25 (red bars) Experiments that display re-emergence each month. Here re-emergence is defined as the Experimental member having a re-emergence region SST of more than $0.9^{\circ} \mathrm{C}$ less that of the mean in the Control run. Time series of ensemble mean NAO index (b) and SST anomaly of the reemergence box. In $\mathbf{b}$ and $\mathbf{c}$ Green is S-C60; Red is $\mathrm{S}-\mathrm{C} 25$ and blue is the observed 2010 minus 2007. The dashed lines indicate $99 \%$ significance levels
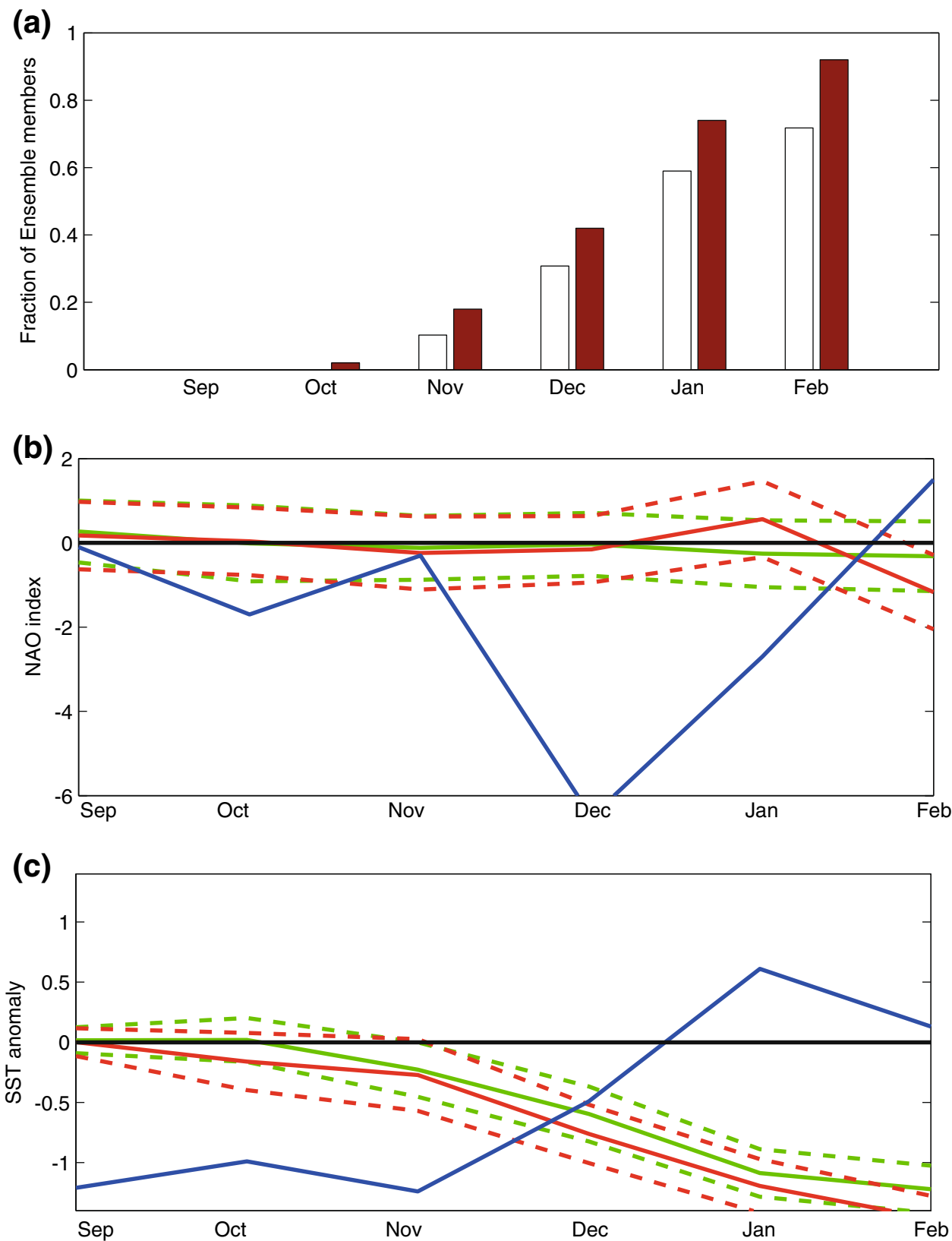

the observed SST difference between 2010 and 2007 is not necessarily all due to re-emergence as other processes such as a weaker ocean heat transport (Cunningham et al. 2013) may have been important. Isolating the relative importance of these two mechanisms for the 2010 event is not the focus here, but could be investigated with an alternative experimental design. Nevertheless, a plausible interpretation for the later change in NAO in the experiments, is that although high atmospheric resolution may be important in bringing subducted SST anomalies to the surface, it is also an important factor in determining how the atmosphere responds to the re-emerged anomalies. However, even with a high resolution atmosphere the signal to noise ratio remains low. The apparent late re-emergence might merely reflect the range of internal variability in the ensemble. Alternatively, it could be due to either insufficient mixing (in the upper ocean) in both forecasts, or it may be because no initial anomaly was placed in the upper $100 \mathrm{~m}$ of the water column. We have investigated this by examining the evolution of the observed temperature profile in the re-emergence region. Specifically, the mean and standard deviation of the September through February potential temperature profiles are plotted along with that from winter in which reemergence occurred (Fig. 12). Compared with the control and anomaly profiles in Figs. 4 and 5 the modelled surface stratification is stronger than observed and the temperature anomaly inserted in the 
Fig. 12 Observed (EN4) September through February potential temperature profiles from 35 ${ }^{\circ} \mathrm{W}, 50^{\circ} \mathrm{N}$ (within the reemergence region): 2000-2011 mean (black line) \pm standard deviation (grey line), 2010-2011 winter
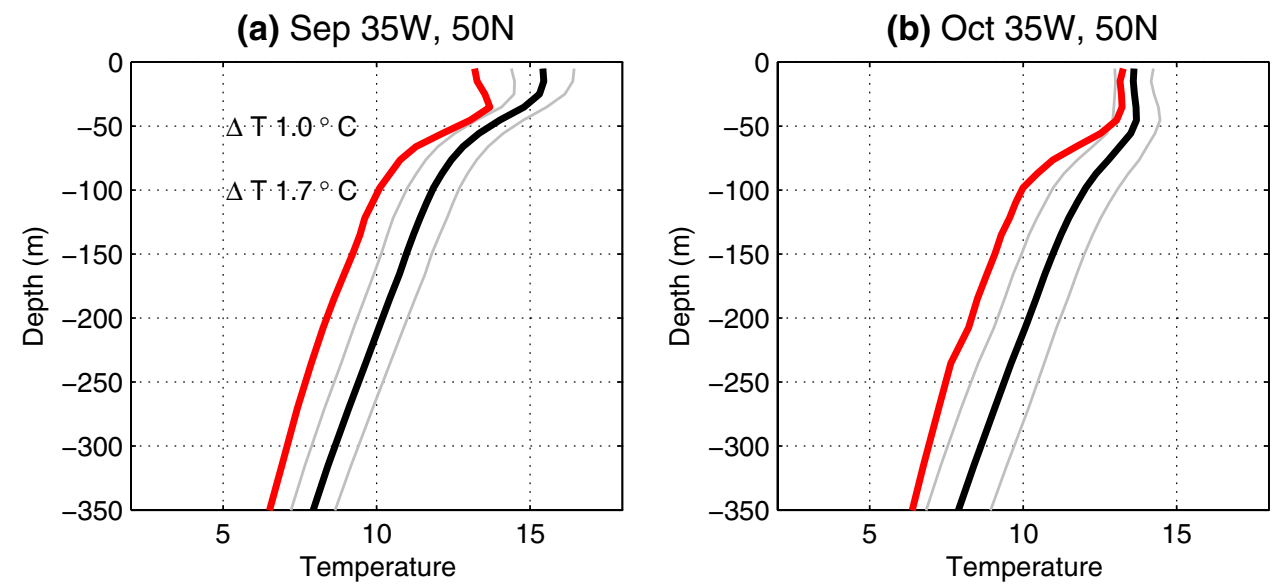

(c) Nov 35W, $50 \mathrm{~N}$

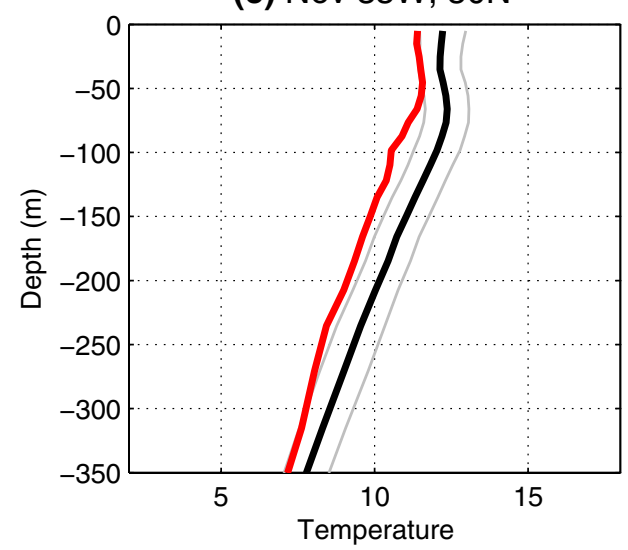

(d) Dec 35W, 50N

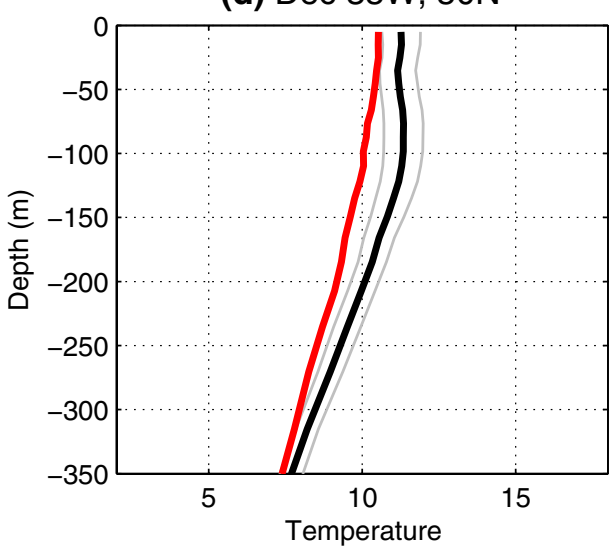

(e) Jan $35 \mathrm{~W}, 50 \mathrm{~N}$
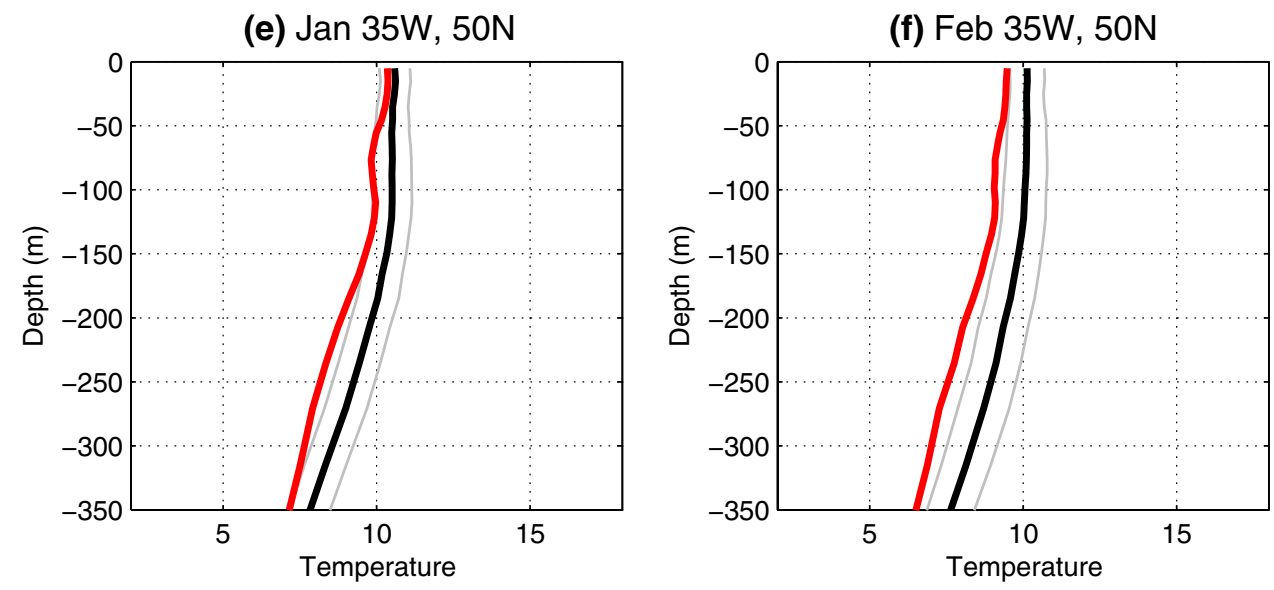

experiment is focused at a greater depth compared to observations. In particular, in a year when there was the reemergence of a cold anomaly (2010-2011), observations indicate that the September observed subsurface anomaly was $0.9^{\circ} \mathrm{C}$ and $0.5^{\circ} \mathrm{C}$ stronger at $50 \mathrm{~m}$ and $100 \mathrm{~m}$ respectively than that prescribed in the experiment (compare Fig. 5a with Fig. 12a). Because the observed anomaly was higher in the water column, a significant anomaly re-emerged more quickly (i.e. by October-November). The timing of the model mixed layer deepening throughout late autumn and winter is similar to that in the observations.

An implication of the later re-emergence in the model is that the difference in the ensemble means will not clearly show the impact of November-December reemergence as most of the experiment members are not reemerging at that point. Similarly, the ensemble mean will not fully reflect the January re-emergence because, although most of the members have reemerged by 
January, over half of these had reemerged first in previous months but maintained an anomalously low SST.

Because we seek to identify the atmospheric impact of reemergence in the coupled seasonal forecast system, we focus on re-emergence in January when there is stronger signal. To clearly highlight the impact of January reemergence it is necessary to examine the SUBSFC ensemble members that reemerge for the first time in January as opposed to the mean of the whole ensemble. Therefore in the next section we examine the anomalous fields associated with the subset of SUBSFC25 members that have re-emerged for the first time in January.

\subsection{January re-emergence}

\subsubsection{SUBSFC60}

We define a subset of ensemble members $(n=8$ for both SUBSFC60 and SUBSFC25) for re-emergence occurring for the first time in January as ensemble members $i$ for which re-emergence index $R(i, \mathrm{dec})>-0.9$ and $R(i, j a n)<$ - 0.9. In SUBSFC60, anomalies associated with the difference between the mean of the January re-emergence subset and the control ensemble mean are shown in Fig. 12. Specifically, the SLP, SAT and surface latent heat flux difference fields are shown for 1 month before re-emergence, the month of re-emergence and 1 month after re-emergence. Prior to re-emergence, the SLP field (Fig. 13a) shows an anomalous low over the Subpolar Gyre. This pattern brings (a) Month -1 SLP (hPa)

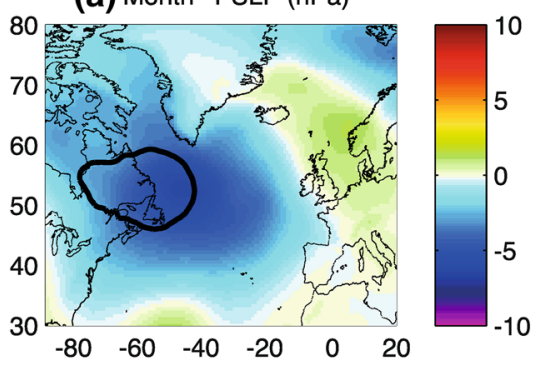

(d) Month -1 Ta (C)

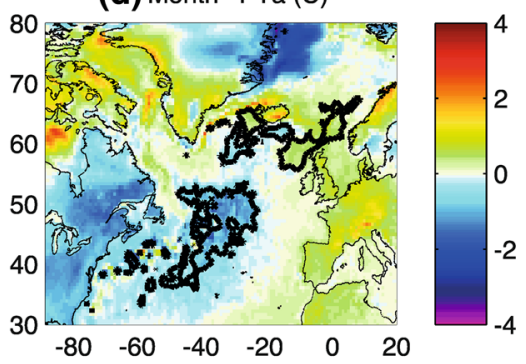

(g) Month -1 LH (Wm-2)

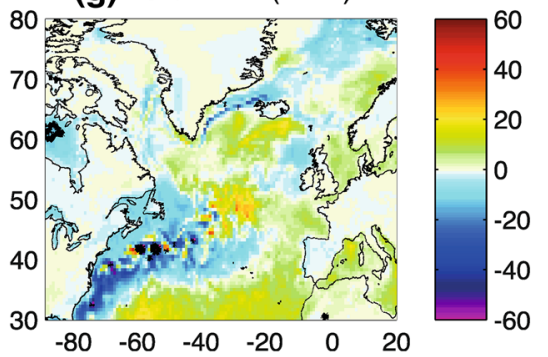

(b) Month 0 SLP (hPa)

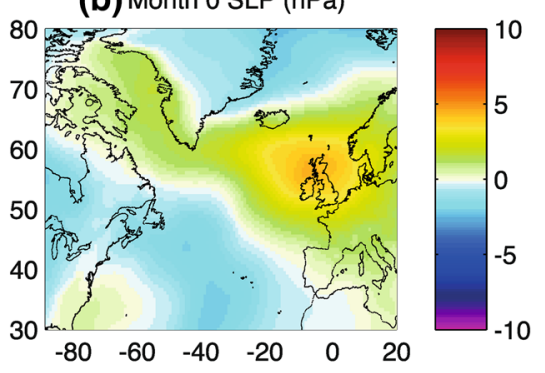

(e) Month $0 \mathrm{Ta}$ (C)

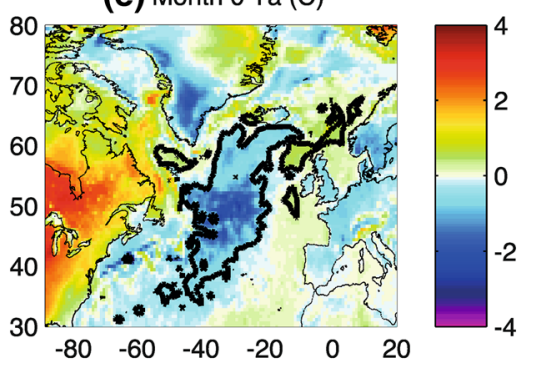

(h) Month $0 \mathrm{LH}\left(\mathrm{Wm}^{-2}\right)$

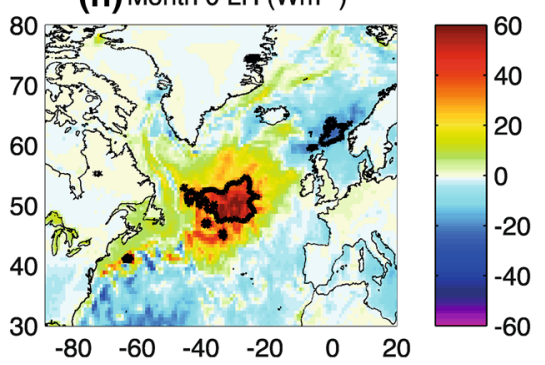

(c) Month +1 SLP (hPa)

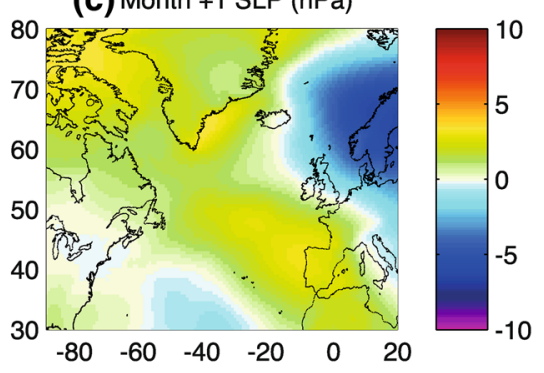

(f) Month +1 Ta (C)

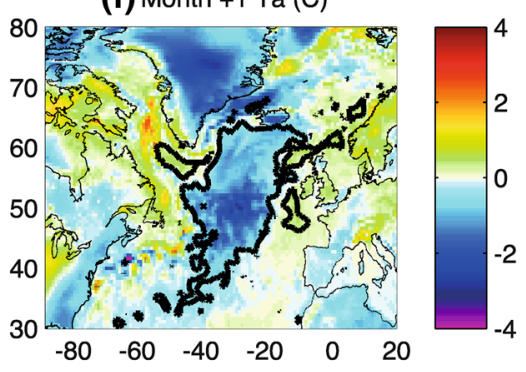

(i) Month +1 LH $\left(\mathrm{Wm}^{-2}\right)$

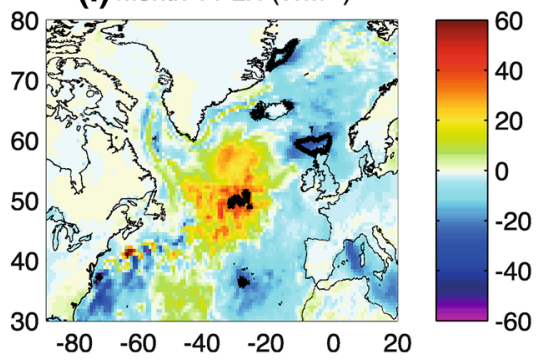

Fig. 13 The mean difference between a subset of SUBSFC60 Experiment ensemble members that re-emerge for the first time in January $(\mathrm{n}=8)$ and the mean of the CONTROL60 ensemble members $(\mathrm{n}=49)$ : month -1 (December) for a SLP $(\mathrm{hPa}), \mathbf{d}$ SAT $\left({ }^{\circ} \mathrm{C}\right)$, g latent heat flux $\left(\mathrm{W} \mathrm{m}^{-2}\right)$; month 0 (January) for b SLP $(\mathrm{hPa})$, e SAT $\left({ }^{\circ} \mathrm{C}\right)$, h latent heat flux $\left(\mathrm{W} \mathrm{m}^{-2}\right)$ and month +1 (February) c SLP (hPa), f
SAT $\left({ }^{\circ} \mathrm{C}\right)$, i latent heat flux $\left(\mathrm{W} \mathrm{m}^{-2}\right)$. In order to test the significance, the difference plots were compared against 10,000 difference plots in which the mean of the subset was calculated by randomly selecting 8 members of the control ensemble with replacement. The contours indicate the difference in the plotted figure was greater than that from the randomly generated difference fields $99 \%$ of the time 
stronger and colder westerly winds over the re-emergence region enhancing turbulent heat loss to cause the necessary mixing. This is supported by the difference in SAT which shows colder temperatures straddling the North American continent and the ocean re-emergence region $\left(40^{\circ} \mathrm{W}, 50^{\circ} \mathrm{N}\right.$ Fig. 13d) and enhanced (negative) latent heat loss near the re-emergence region $\left(50^{\circ} \mathrm{W}-30^{\circ} \mathrm{W}, 40^{\circ} \mathrm{N}-55^{\circ} \mathrm{N}\right.$ Fig. $\left.13 \mathrm{~g}\right)$, a small area of which is significant. During the month of reemergence (month 0 ) and the month following re-emergence $($ month +1$)$, the low pressure over the SPG weakens and there appears to be no significant response of the atmospheric circulation (Fig. 13b, c). However, the negative SAT anomaly strengthens and broadens (Fig. 13e, f). According to the anomalous SLP pattern (Fig. 13b, c), the development of the SAT anomaly over the ocean is not supported by cold air advection from North America during month 0 and month +1 . However the SAT anomaly is consistent with cold air advection from continental Europe in month 0 (Fig. 13b) and the significant reduction in heat flux from the ocean in month 0 and month +1 (Fig. 13h, i). This reduced ocean heat loss is consistent with the lower SSTs that occur as a consequence of re-emergence and would affect sensible heat and longwave as well as latent heat. So in summary, although at this resolution, a pressure pattern that brings cold air over the re-emergence region precedes the re-emergence by a month, there does not appear to be a significant response to the atmospheric circulation in subsequent months. However, re-emergence does result in both the development of a negative SAT anomaly and a switch from enhanced to suppressed latent heat loss from the ocean.

\subsubsection{SUBSFC25}

At the higher resolution, there are more significant anomalies in the surface fields associated with January re-emergence. Considering first the fields for the month before reemergence (Fig. 14a, d, g), anomalous low pressure over the SPG (Fig. 14a), weakly projecting onto the positive NAO pattern, is indicative of the advection of anomalously cold air over the re-emergence region, consistent with the lower temperatures (Fig. 14d) and stronger turbulent heat loss (Fig. 14g). During the month of re-emergence, the low pressure over the SPG weakens and broadens (Fig. 14a) and the negative SAT anomaly over the SPG strengthens and broadens (Fig. 14e). The shape of this anomaly, with cold air also found over Northeast America and southern Greenland suggests continued anomalous advection of continental/ Arctic air masses towards the reemergence region. However, the fact that the enhanced surface heat flux into the atmosphere over the re-emergence region disappears (Fig. 14h) also promotes lower SAT over the southern SPG. Further to the east, near the British Isles there is still some enhanced latent heat flux (Fig. 14h) consistent with the weak positive NAO type SLP pattern (Fig. 14b).

At lag +1 month a large area along the eastern flank of the SPG from $45^{\circ} \mathrm{N}$ to $65^{\circ} \mathrm{N}$ has significantly reduced heat loss to the atmosphere (Fig. 14i). This change is consistent with the decrease in SST that occurs with re-emergence. The reduction in latent heat loss is as much as $50 \mathrm{~W} \mathrm{~m}^{-2}$ and encompasses some of the region that experiences enhanced heat loss at lag -1 and the area immediately to the north. The SAT anomaly strengthens slightly between lag 0 and lag +1 months (Fig. 14f). There is no longer a negative anomaly over Greenland and the North American continent. This is linked to a significant change in the SLP at month +1 . The change consists of anomalous high pressure downstream (northeastward) of the re-emergence region and a low pressure anomaly to the south (Fig. 14c). This change is consistent with a significant shift towards negative NAO conditions. This prevents anomalous cold air advection from North America contributing to the negative SAT anomaly over the reemergence region. Over land the SAT anomalies show the patterns expected during a negative NAO phase with cold anomalies over Western and Northwestern Europe and warmer than average conditions over Greenland and Northeast America.

The evidence of SUBFC25 is that re-emergence of SST anomalies can reduce heat loss to the atmosphere, lower the SAT and impact the atmospheric circulation. The impact in month +1 projects strongly onto the negative NAO pattern. In month 0 the situation is more ambiguous. The weak projection onto the positive NAO pattern may partly reflect the fact that we have selected a re-emerging subset and we expect re-emergence to require (broadly) positive NAO conditions. Set against this is the fact that the pressure pattern shows a significant response compared to the control simulation in some regions, suggesting it is caused to some extent by the introduction of the perturbation.

Numerous observational and modelling studies (e.g. Kuo et al. 1991; Rausch and Smith 1996; Davis and Emanuel 1988) have suggested that withholding turbulent fluxes atmospheric models (which appears to be the first order effect of re-emergence Fig. 14i) leads to a reduction in the strength of mid-latitude cyclones that develop over the Atlantic. It is therefore possible that the anomalously high pressure downstream of the re-emergence in Fig. 14c is the net effect of a reduction in cyclone strength due to suppressed turbulent fluxes. Similarly, Scaife et al. (2011) showed that a cold bias in GCMs north-west of this region could significantly impact the jet stream and the blocking associated with a negative NAO. Another possible mechanism, described by Peng et al. (2003) involves a reduction in diabetic heating leading to a downstream pressure anomaly. Cassou et al. (2007) simulated re-emergence in an atmospheric model coupled to a mixed layer ocean model and 
(a) Month -1 SLP (hPa)

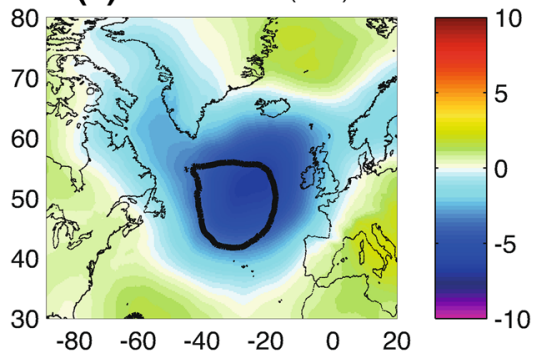

(d) Month -1 $\mathrm{Ta}$ (C)

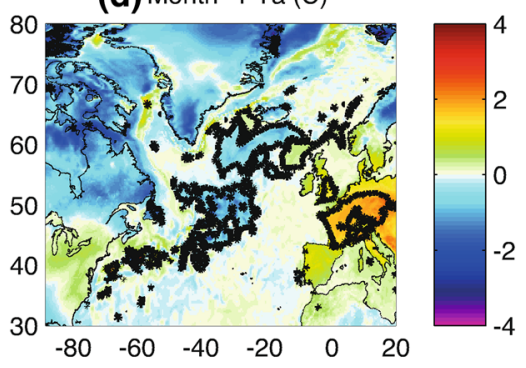

(g) Month -1 LH $\left(\mathrm{Wm}^{-2}\right)$

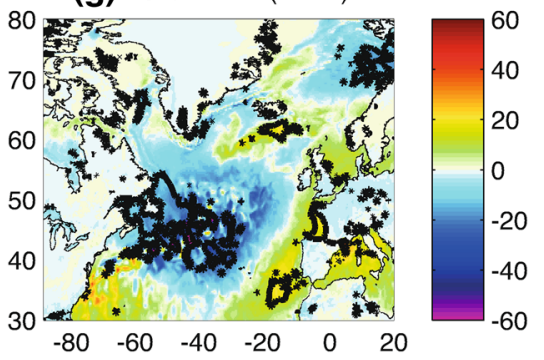

(b) Month 0 SLP (hPa)

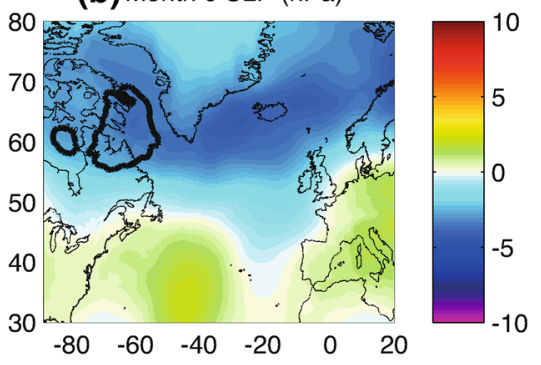

(e) Month $0 \mathrm{Ta}$ (C)

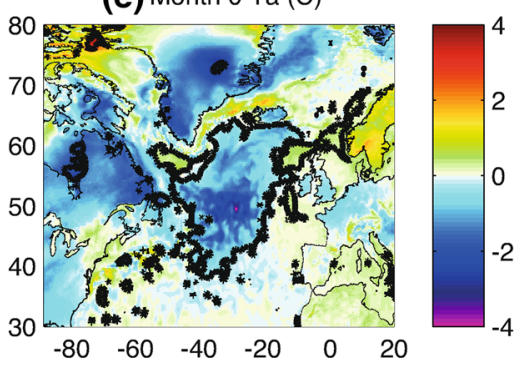

(h) Month $0 \mathrm{LH}\left(\mathrm{Wm}^{-2}\right)$

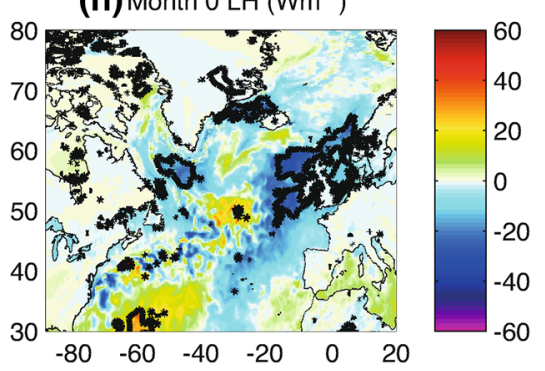

(c) Month +1 SLP (hPa)

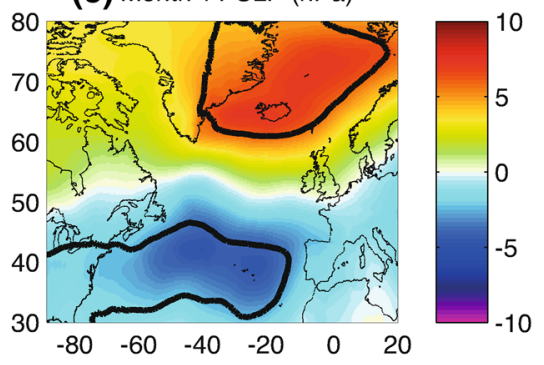

(f) Month +1 Ta (C)

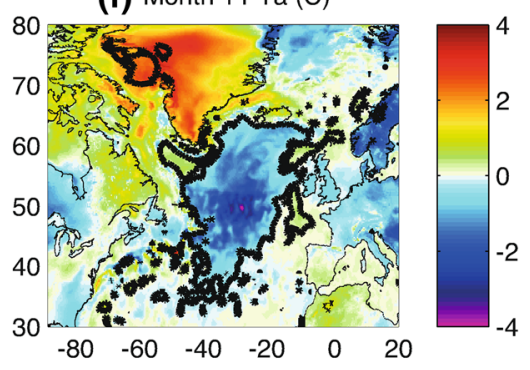

(i) Month $+1 \mathrm{LH}\left(\mathrm{Wm}^{-2}\right)$

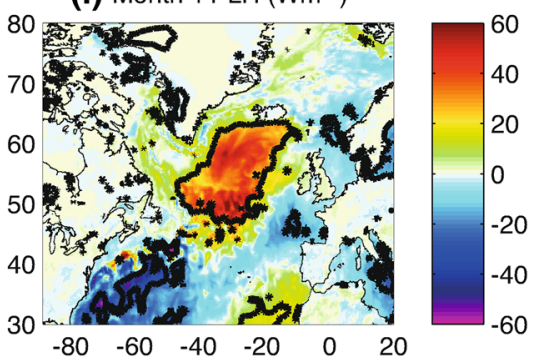

Fig. 14 The mean difference between a subset of SUBSFC25 Experiment ensemble members that re-emerge for the first time in January $(\mathrm{n}=8)$ and the mean of the CONTROL25 ensemble members $(\mathrm{n}=48)$ : month -1 (December) for a SLP $(\mathrm{hPa}), \mathbf{d}$ SAT $\left({ }^{\circ} \mathrm{C}\right)$, g latent heat flux $\left(\mathrm{W} \mathrm{m}^{-2}\right)$; month 0 (January) for b SLP $(\mathrm{hPa})$, e SAT $\left({ }^{\circ} \mathrm{C}\right)$, h latent heat flux $\left(\mathrm{W} \mathrm{m}^{-2}\right)$ and month +1 (February) c SLP (hPa), f
SAT $\left({ }^{\circ} \mathrm{C}\right)$, i latent heat flux $\left(\mathrm{W} \mathrm{m}^{-2}\right)$. In order to test the significance, the difference plots were compared against 10,000 difference plots in which the mean of the subset was calculated by randomly selecting 8 members of the control ensemble with replacement. The contours indicate the difference in the plotted figure was greater than that from the randomly generated difference fields $99 \%$ of the time hypothesized that the mechanism by which SST anomalies impacted the atmospheric circulation was by strengthening or weakening the SST gradient which in turn strengthens or weakens the baroclinic growth rate of mid-latitude storms. They found the atmospheric impact of re-emergence was to reinforce the particular phase of the previous winters NAO. Cassou et al. (2007) pointed out that their proposed mechanism is sensitive to the size, shape and location of the re-emerging anomaly, it being important for the anomalous SST gradient to have sufficient strength and size and for it to coincide with the position of the storm track. Sensitivity to the characteristics of the re-emerging anomaly may also be important to the other proposed mechanisms.

Although a detailed investigation of the mechanism is deferred to future work, additional analysis of relevant eddy covariances is consistent with a hypothesis that suppressed turbulent fluxes impact the pressure field by leading to diminished cyclone growth. Figure 15a shows the anomalous convective precipitation at month +1 after a January re-emergence along with the location of the upper level (westerly) jet stream. There is a suppression of atmospheric convection (indicated by convective rainfall) directly over the reemergence region of reduced latent heat flux (Fig. 14i) and a significant reduction in the eddy kinetic energy (Fig. 15b) downstream east and north of Iceland. Both of these features are consistent with suppressed latent heat flux leading to reduced cyclone growth rate and weaker cyclones. Weaker cyclones are also consistent with a higher pressure in the same region (Fig. 14c). Examination of the eddy-covariance terms provides further evidence of the role of eddies. There is a reduction of the Jet Stream speed around $40^{\circ} \mathrm{W}-55^{\circ} \mathrm{W}$ (Fig. 15c), which is co-located with 

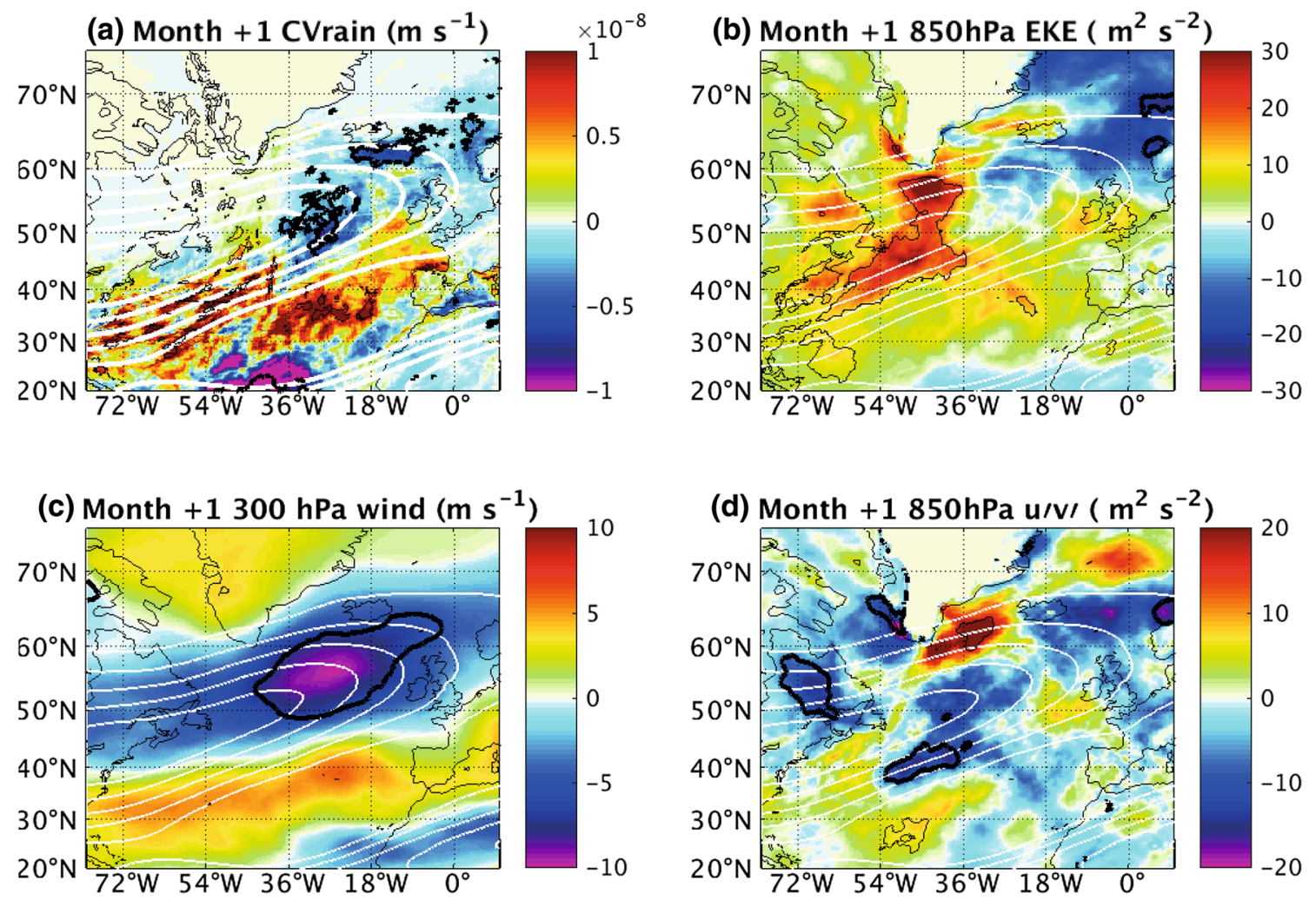

Fig. 15 The mean difference between a subset of SUBSFC25 experiment ensemble members that re-emerge for the first time in January $(\mathrm{n}=8)$ and the mean of the CONTROL25 ensemble members $(\mathrm{n}=48)$ : for month +1 : a convective rainfall $\left(\mathrm{m} \mathrm{s}^{-1}\right)$; $\mathbf{b}$ Eddy kinetic energy $\left(\mathrm{m}^{2} \mathrm{~s}^{-2}\right)$; c $300 \mathrm{hPa}$ wind speed $\left(\mathrm{m} \mathrm{s}^{-1}\right)$; d $850 \mathrm{hPa} u^{\prime} v^{\prime}\left(\mathrm{m}^{2}\right.$

$\mathrm{s}^{-2}$ ). The white contours indicate the location of the Jet Stream, (contours are $15,20,25,30$ and $35 \mathrm{~m} \mathrm{~s}^{-1}$ ). The contours indicate the difference in the plotted figure was greater than that from the randomly generated difference fields $99 \%$ of the time

anomalous divergence in $u^{\prime} v^{\prime}$ (Figs. 15d, 16a), $u^{\prime} v^{\prime}$ having positive values to the north and negative values to the south. This indicates the eddies are weakening or providing less energy to the jet at this location. In accordance with geostrophy, a weakened jet would be accompanied by an adiabatic decrease in the pressure gradient tending the atmospheric circulation towards the pattern seen in Fig. 14c.

Summarizing the anomalous fields associated with reemergence in SUBSFC25, the month - 1 (and to a certain extent month 0) fields suggest that a SLP anomaly that brings stronger winds, colder (typically drier) air and enhanced turbulent heat loss to the re-emergence region is required to initiate the re-emergence. In response to reemergence (month +1 ), the latent heat flux and convective rainfall is damped by the lower SST. In addition, a positive SLP anomaly, consistent with damped fluxes suppressing cyclone development and adiabatic adjustment to an eddyinduced weakening, appears to the north and east of the reemergence region over Iceland. The surface fields are similar to those with SUBSFC60, but only at the higher atmospheric resolution is there a significant response (at lag +1 month) in the latent heat flux and the atmospheric circulation.

\section{Summary and conclusions}

Given information on the distribution of any end-ofsummer subsurface temperature anomaly, it is reasonable to anticipate the re-emergence of this anomaly as the ocean mixed layer deepens the following autumn and winter. Accurate prediction of re-emergence events could potentially improve forecast skill in seasonal predictions. In order to understand any potential increase in seasonal predictability afforded by subsurface ocean temperature anomaly re-emergence, experiments simulating the process in a state of the science forecast system have been conducted. Specifically, temperature anomalies were inserted below the September 1 mixed layer in the initial conditions of a 6-month integration. The analysis of the difference between the SUBSFC and CONTROL ensemble means revealed that as the winter mixed layer deepened, the colder anomaly was mixed to the surface, creating a negative SST anomaly over the Subpolar Gyre. The SUBSFC mean SST becomes significantly cooler than that in CONTROL by November and continues to spread and strengthen through the winter up to February. The 


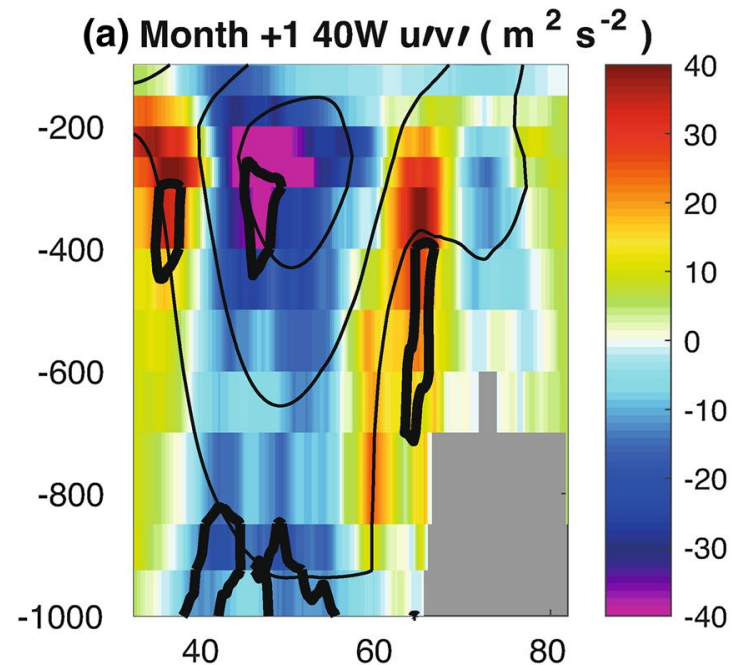

Fig. 16 The mean difference between a subset of SUBSFC25 experiment ensemble members that re-emerge for the first time in January $(\mathrm{n}=8)$ and the mean of the CONTROL25 ensemble members $(\mathrm{n}=48)$ : for month +1 for latitude-depth cross section of $u^{\prime} v^{\prime}\left(\mathrm{m}^{2}\right.$

decrease in SST was also accompanied by a suppression of net heat loss to the atmosphere and a reduction of the SAT.

An examination of individual ensemble members revealed that not all ensemble members simulated re-emergence. Of those members that did simulate re-emergence, there was a considerable range in the times when re-emergence occurred. For example, in the SUBSFC25 experiment, in November only $20 \%$ of ensemble members simulate reemergence, this number increases to $77 \%$ by January and is over 90\% in February. Observed re-emergence events display peak pattern correlations in November (e.g. Cassou et al. 2007), earlier on average than (albeit still within the spread of) the simulated re-emergence. Any impact on the regional climate might also be expected to be correspondingly earlier than simulated in numerical experiments.

The re-emergence results in a significant shift of the NAO index towards a negative phase in month +1 in the higher resolution seasonal forecast experiment. The shift occurs later (by about 2 months) than is suggested by observations and is of much weaker magnitude than observed anomalies in 2010. If the observed shift to a negative NAO was the result of North Atlantic SST anomalies, as concluded by Buchan et al. (2014), then it would seem likely that the later NAO shift in the experiments is related to the later simulated re-emergence. The weak amplitude of the NAO signal may be a result of the known weak signal to noise ratio of the GloSea5 seasonal forecast system (Eade et al. 2014). The lack of response in the lower resolution experiment suggests that higher atmospheric resolution amplifies the transfer of the signal from the ocean to the atmosphere. Specifically the experiments showed that re-emergence in the $25 \mathrm{~km}$ atmosphere leads to a significantly

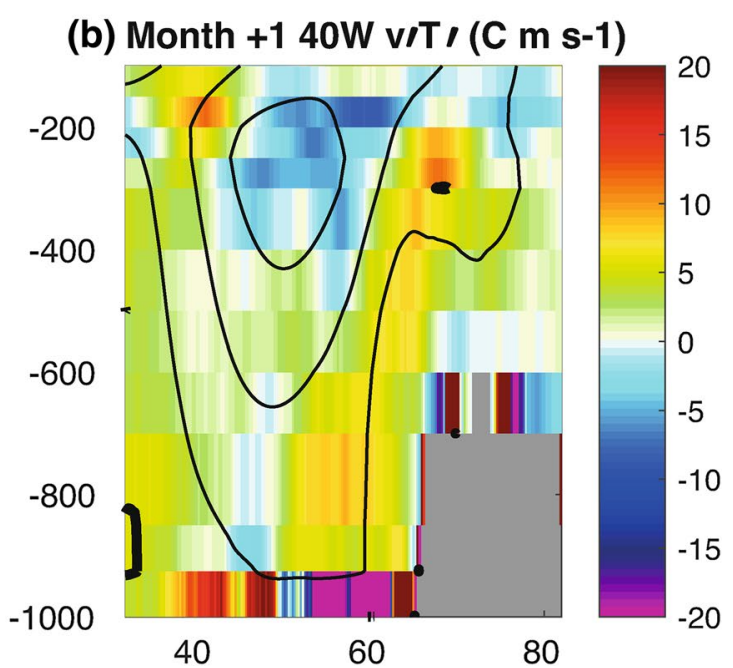

$\mathrm{s}^{-2}$ ) at $40^{\circ} \mathrm{W}\left(\right.$ a) and $5^{\circ} \mathrm{W}(\mathbf{b})$. The thin black contours denote the 10 , 20 and $30 \mathrm{~m} \mathrm{~s}^{-1}$ contours of wind speed. The thick black contours indicate the difference in the plotted figure was greater than that from the randomly generated difference fields $99 \%$ of the time

greater suppression of net heat flux to the atmosphere in the northern subpolar gyre than in the $60 \mathrm{~km}$ atmosphere. In this context we note that Roberts et al. (2018) found little difference in the climatological surface heat fluxes of the $50 \sim \mathrm{km}$ and $25 \sim \mathrm{km}$ versions of the ECMWF Integrated forecast system. While Roberts et al. (2016) found only modest differences in point-by-point SST-net heat flux relationship in the North Atlantic between a N512 atmosphere/1/12th degree ocean and N216 atmosphere and 1/4th degree ocean version of HadGEM3. However, in the region where we found significant differences between 60 and $25 \mathrm{~km}$ resolutions, Duvivier and Cassano (2013) found a more notable resolution dependence of surface winds. They correlated surface variables from different resolutions of a WRF model with that from an intensive aircraft based observation campaign. They found increased correlations with observations in the surface winds and turbulent fluxes at $25 \mathrm{~km}$ resolution relative to $50 \mathrm{~km}$, with further improvements when resolution was increased to $10 \mathrm{~km}$. These and the results of the present study, are consistent with higher resolution in either or both of the atmosphere or ocean component of the forecast system leading to a stronger (i.e. more realistic) response with a correspondingly more realistic (stronger) impact over land areas of the UK, Europe and Africa.

In order to take account of the variable time of re-emergence, ensemble members that display re-emergence for the first time in January were examined as a subset. From this analysis it was evident that specific conditions favour reemergence. In particular re-emergence is set up (month lag - 1) by an atmospheric pattern that brings, stronger winds, colder and drier air and stronger oceanic latent heat loss to 
the mid-latitude Atlantic. With the shape of the prescribed anomaly in this experiment (Fig. 1), this atmospheric pattern has a positive NAO index (Figs. 11b, 14a) and the response had a negative NAO index. However, the nature of the atmospheric pattern required to initiate re-emergence (and its subsequent response) will be highly dependent on the shape, strength and depth of the initial ocean temperature anomaly. For example, re-emergence of a deep, cold western subtropical temperature anomaly might require an atmospheric pattern with a negative NAO index. In terms of the response to re-emergence, this was characterised by lower SSTs, colder SAT, reduced latent heat loss and reduced atmospheric convection. A response only seen with the high resolution $(\sim 25 \mathrm{~km}, \mathrm{~N} 512)$ atmosphere was the formation of positive SLP anomalies downstream. This is consistent with a reduction in surface turbulent fluxes reducing the growth rate of mid-latitude Atlantic cyclones. Analysis of eddy-covariances suggest that eddies extract energy from the mean flow and leading to an adiabatic decrease in the meridional pressure gradient also supporting the shift towards a more negative phase of the NAO.

Overall, this analysis of GloSea5 indicates that given the summer sub-mixed layer temperature anomalies in the ocean, a pattern of re-emergence and the corresponding impact on SAT, anomalies in the net heat flux and the atmospheric circulation may be predicted at a seasonal time scale. We note, however, that a significant response in the atmospheric circulation was only found with the higher resolution atmosphere. In addition, it is also evident that the existence of a summer sub-mixed layer anomaly does not guarantee re-emergence, but that specific autumn/early winter atmospheric conditions are required before subsurface anomalies can have an impact on the atmosphere and in turn seasonal forecasts.

Acknowledgements JPG, BS, SAJ, JJM, ATB, and ALN were funded by 'The North Atlantic Climate System Integrated Study: ACSIS', programme (NE/N018044/1) of the Natural Environment Research Council of the UK and by the UK-China Research and Innovation Partnership Fund through the Met Office Climate Science for Service Partnership (CSSP) China as part of the Newton Fund. The data presented in this paper is available from the corresponding author upon request.

Open Access This article is distributed under the terms of the Creative Commons Attribution 4.0 International License (http://creativeco mmons.org/licenses/by/4.0/), which permits unrestricted use, distribution, and reproduction in any medium, provided you give appropriate credit to the original author(s) and the source, provide a link to the Creative Commons license, and indicate if changes were made.

\section{References}

Blaker AT, Hirschi JJ-M, McCarthy G, Sinha B, Taws S, Marsh R, Coward A, de Cuevas B (2015) Historical analogues of the recent extreme minima observed in the Atlantic meridional overturning circulation at 26N. Clim Dyn 44:457-473. https://doi.org/10.1007/ s00382-014-2274-6

Bojariu R, Gimeno L (2003) Predictability and numerical modeling of the North Atlantic Oscillation. Earth Sci Rev 64:145-168. https:// doi.org/10.1016/S0012-8252(03)00036-9

Bowler NE, Arribas A, Beare SE, Mylne KR, Shutts GJ (2009) The local ETKF and SKEB: upgrades to the MOGREPS short-range ensemble prediction system. Q J R Meteorol Soc 135:767-776. https://doi.org/10.1002/qj.394

Buchan J, Hirschi JJ-M, Blaker AT, Sinha B (2014) North Atlantic SST Anomalies and the cold north European weather events of winter 2009-10 and December 2010. Mon Weather Rev 142:922-932. https://doi.org/10.1175/MWR-D-13-00104.1

Cassou C, Deser C, Alexander MA (2007) Investigating the impact of reemerging sea surface temperature anomalies on the winter atmospheric circulation over the North Atlantic. J Clim 20:3510-3526. https://doi.org/10.1175/JCLI4202.1

Cunningham SA, Roberts CD, Frajka-William E, Johns WE, Hobbs W, Palmer MD, Rayner D, Smeed DA, McCarthy G (2013) Atlantic Meridional overturning circulation slowdown cooled the subtropical ocean. Geophys Res Letts 40:6202-6207. https ://doi.org/10.1002/2103GL058464

Czaja A, Frankignoul C (2002) Observed impact of Atlantic anomalies on the North Atlantic oscilliation. J Clim 15:606-623. https://doi.org/10.1175/1520-0442(2002)015\%3c0606:OIOAS A\%3e2.0.CO;2

Davis CA, Emanuel KA (1988) Observational evidence for the influence of surface heat fluxes on rapid maritime cyclogenesis. Mon Weather Rev 116:2649-2659. https://doi.org/10.1175/15200493(1988)116\%3c2649:OEFTIO\%3e2.0.CO;2

Dee DP, Uppala SM, Simmons AJ, Berrisford P, Poli P, Kobayashi S, Andrae U, Balmaseda MA, Balsamo G, Bauer P, Bechtold P, Beljaars ACM, van de Berg L, Bidlot J, Bormann N, Delsol C, Dragani R, Fuentes M, Geer AJ, Haimberger L, Healy SB, Hersbach H, Hólm EV, Isaksen L, Kållberg P, Köhler M, Matricardi M, McNally AP, Monge-Sanz BM, Morcrette JJ, Park BK, Peubey C, de Rosnay P, Tavolato C, Thépaut J-N, Vitart F (2011) The ERA-Interim reanalysis: configuration and performance of the data assimilation system. Q J R Meteorol Soc 137:553-597. https://doi.org/10.1002/qj.828

Duvivier AK, Cassano JJ (2013) Evaluation of WRF model resolution on simulated mesoscale winds and surface fluxes near Greenland. Mon Weather Rev 141:941-963. https://doi. org/10.1175/MWR-D-12-0009.1

Eade R, Smith D, Scaife AA, Wallace E (2014) Do seasonal to decadal climate predictions underestimate the predictability of the real world? Geophys Res Letts 41:5620-5628. https://doi. org/10.1002/2014GL061146

Fereday DR, Maidens A, Arribas A, Scaife AA, Knight JR (2012) Seasonal forecasts of northern hemisphere winter 2009/10. Env Res Lett 7:034031

Gray LJ, Woolings TJ, Andrews M, Knight J (2016) Eleven-year solar cycle signal in the NAO and Atlantic/European blocking. Q J R Meteorol Soc 143:1890-1903. https://doi.org/10.1002/ qj2782

Grist JP, Josey SA, Jacobs ZL, Marsh R, Sinha B, van Sebille E (2016) Extreme air-sea interaction over the North Atlantic subpolar gyre during the winter of 2013-14 and its sub-surface legacy. Clim Dyn 46:4027-4045. https://doi.org/10.1007/s0038 2-015-2819-3

Hewitt HT et al (2016) The impact of resolving the Rossby radius at mid-latitudes in the ocean: results from a high-resolution version of the Met Office GC2 coupled model. Geosci Model Dev 9:3655-3670. https://doi.org/10.5194/gmd-9-3655-2016

Hewitt HT, Bell MJ, Chassignet EP, Czaja A, Ferreira D, Griffes SM, Hyder P, McClean JL, New AL, Roberts MJ (2017) Will 
high-resolution global ocean models benefit coupled predictions on short-range to climate timescales? Ocean Model 120:120-136. https://doi.org/10.1016/j.ocemod.2017.11.002

Hunke EC, Lipscomb WH (2010) 'CICE: The sea ice model documentation and software user's manual, version 4.1', Technical report LA-CC-06-012. Los Alamos National Laboratory: Los Alamos, NM, p 76

Ineson S, Scaife AA (2009) The role of the stratosphere in the European climate response to El Nino. Nat Geosci 2:32-36. https:// doi.org/10.1038/ngeo381

Kumar A, Chen M (2017) Causes of skill in seasonal predictions of the Arctic Oscillation. Clim Dyn. https://doi.org/10.1007/s0038 2-017-4019-9

Kuo YH, Reed RJ, Lowman S (1991) Effects of surface-energy fluxes during the early development and rapid intensification stages of 7 explosive cyclones in the western Atlantic. Mon Weather Rev 119:457-476. https://doi.org/10.1175/15200493(1991)119\%3c0457:EOSEFD\%3e2.0.CO;2

MacLachlan C, Arribas A, Peterson KA, Maidens A, Fereday D, Scaif AA, Gordon M, Vellinga M, Williams A, Comer RE, Camp J, Xavier P, Madec G (2015) Global Seasonal forecast system version 5 (GloSea5): a high-resolution seasonal forecast system. Q J R Meteorol Soc 141:1072-1084. https://doi.org/10.1002/qj.2396

Madec G (2008) NEMO Ocean Engine, Note du Pole de Modelisation, vol. 27, 1288-1619, Inst. Pierre-Simon Laplace, Paris, France

Maidens A, Arribas A, Scaife AA, Maclachlan C, Peterson D, Knight J (2013) The influence of surface forcings on prediction of the North Atlantic oscillation regime of winter 2010/11. Mon Weather Rev 141:3801-3813. https://doi.org/10.1175/MWR-D-13-00033.1

Marshall AG, Scaife AA (2009) Impact of the QBO on surface winter climate. J Geophys Res Atmos 114:D18110. https://doi. org/10.1029/2009JD011737

McCarthy GD, Frajka-Williams E, Johns WE, Baringer MO, Meinen CS, Bryden HL, Rayner D, Duchez A, Roberts C, Cunningham SA (2012) Observed interannual variability of the Atlantic meridional overturning circulation at $26.5^{\circ} \mathrm{N}$. Geophys Res Lett 39:5. https://doi.org/10.1029/2012g1052933

Megann A, Storkey D, Aksenov Y, Alderson S, Calvert D, Graham T, Hyder P, Siddorn J, Sinha B (2014) GO5.0: the joint NERCMet Office NEMO global ocean model for use in coupled and forced applications. Geosci Model Dev 7:1069-1092. https://doi. org/10.5194/gmd-7-1069-2014

Minobe S, Kuwano-Yoshida A, Komori N, Xie S-P, Small RJ (2008) Influence of the Gulf Stream on the troposphere. Nature. https:// doi.org/10.1038/nature00660

Parfitt R, Czaja A, Minobe S, Kuwano-Yoshida A (2016) The atmospheric frontal response to SST perturbations in the Gulf Stream region. Geophys Res Letts 43:2299-2306. https://doi. org/10.1002/2016GL067723

Peng S, Robinson WA, Li S (2003) Mechanisms for the NAO responses to the North Atlantic SST tripole. J Clim 16:1987-2003

Rae JGL, Hewitt HT, Keen AB, Ridley JK, West AE, Harris CM, Hunke EC, Walters DN (2015) Development of the Global Sea Ice 6.0 CICE configuration for the Met Office Global Coupled model. Geosci Model Dev 8:2221-2230. https://doi.org/10.5194/ gmd-8-2221-2015

Rausch RLM, Smith PJ (1996) A diagnosis of a model-simulated explosively developing extratropical cyclone. Mon Weather Rev 124:875-904. https://doi.org/10.1175/15200493(1996)124\%3c0875:ADOAMS\%3e2.0.CO;2

Roberts MJ, Hewitt HT, Hyder P, Ferreira D, Josey SA, Mizielinski M, Shelly A (2016) Impact of ocean resolution on coupled airsea fluxes and large-scale climate. Geophys Res Lett 43:10430 10438. https://doi.org/10.1002/2016g1070559

Roberts CD, Senan R, Molteni F, Boussetta S, Mayer M, Keeley S (2018) Climate model configurations of the ECMWF integrated forecast system (ECWMF-IFS cycle 43r1) for HighResMIP. Geosci Model Dev Disc. https://doi.org/10.5194/gmd-2018-90

Rodwell MJ, Rowell DP, Folland CK (1999) Oceanic forcing of the wintertime North Atlantic Oscillation and European climate. Nature 398:320-323. https://doi.org/10.1038/18648

Scaife AA, Copsey D, Gordon C, Harris C, Hinton T, Keeley S, O' Neil A, Roberts M, Williams K (2011) Improved Atlantic winter blocking in a climate model. Geophys Res Let 38:L23703. https ://doi.org/10.1029/2011GL049573

Scaife AA, Arribas, A, Blockley E, Brookshaw A, Clark RT, Dunstone N, Eade R, Fereday D, Folland CK, Gordon M, Hermanson L, Knight JR, Lea DJ, MacLachlan C, Maidens A, Martin M, Peterson AK, Smith, D, Vellinga M, Wallace E, Waters J (2014) Skillful long-range prediction of European and North American winters. Geophys Res Let 41:2514-2519

Scaife AA, Comer RE, Dunstone NJ, Knight JR, Smith DM, MacLachlan C, Martin N, Peterson KA, Rowlands D, Carroll EB, Belcher S, Slingo J (2017) Tropical rainfall, Rossby waves and regional winter climate predictions. Q J R Meteorol Soc 143:1-11. https ://doi.org/10.1002/qj.2910

Siegert S, Stephenson DB, Sansom PG, Scaife AA, Eade A, Arribas A (2016) A Bayesian Framework for verification and recalibration of ensemble forecasts. How uncertain is NAO predictability? J Clim 29:995-1012. https://doi.org/10.1175/JCLI-D-15-0196.1

Taws SL, Marsh R, Wells NC, Hirschi J (2011) Re-emerging ocean temperature anomalies in late-2010 associated with a repeat negative NAO. Geophys Res Lett 38(20):L20601. https://doi. org/10.1029/2011GL048978

Walters DN, Best MJ, Bushell AC, Copsey D, Edwards JM, Falloon PD, Harris CM, Lock AP, Manners JC, Morcrette CJ, Roberts MJ, Stratton RA, Webster S, Wilkinson JM, Willett MR, Boutle IA, Earnshaw PD, Hill PG, MacLachlan C, Martin GM, MoufoumaOkia W, Palmer MD, Petch JC, Rooney GG, Scaife AA, Williams KD (2011) The Met Office Unified Model Global Atmosphere 3.0/3.1 and JULES global land 3.0/3.1 configurations. Geosci Model Dev 4:919-941. https://doi.org/10.5194/gmd-4-919-2011

Walters D, Boutle I, Brooks M, Melvin T, Stratton R, Vosper S, Wells H, Williams K, Wood N, Allen T, Bushell A, Copsey D, Earnshaw P, Edwards J Gross M, Hardiman S, Harris C, Heming J, Klingaman N, Levine R, Manners J, Martin G, Milton S, Mittermaier M, Morcrette C, Riddick T, Roberts M, Sanchez C, Selwood P, Stirling A, Smith C, Suri D, Tennant W, Vidale PL, Wilkinson J, Willett M, Woolnough S, Xavier P (2017) The Met Office Unified model global atmosphere 6.0/6.1 and JULES Global Land 6.0/6.1 configurations. Geosci Model Dev 10:1487-1520. https ://doi.org/10.5194/gmd-10-1487-2017

Waters J, Lea DJ, Martin MJ, Mirouze I, Weaver A, While J (2015) Implementing a variational data assimilation system in an operational 1/4 degree global ocean model. Q J R Meteorol Soc 141:333-349. https://doi.org/10.1002/qj.2388

Williams A (2014) Skillful long-range prediction of European and North American winters. Geophys Res Letts 41:2514-2519. https ://doi.org/10.1002/2014GL059637

Williams KD, Harris CM, Bodas-Salcedo A, Camp J, Comer RE, Copsey D, Fereday D, Graham T, Hill R, Hinton T, Hyder P, Ineson S, Masato G, Milton SF, Roberts MJ, Rowell DP, Sanchez C, Shelly A, Sinha B, Walters DN, West A, Woollings T, Xavier PK (2015) The Met Office Global Coupled model 2.0 (GC2) configuration. Geosci Model Dev 8:1509-1524. https://doi.org/10.5194/ gmd-8-1509-2015

Publisher's Note Springer Nature remains neutral with regard to jurisdictional claims in published maps and institutional affiliations. 